\title{
A Parametric Investigation of Nozzle Planform and Internal / External Geometry at Transonic Speeds
}

\author{
Daniel L. Cler* \\ NASA Langley Research Center, Hampton, Virginia
}

\section{ABSTRACT}

An experimental investigation of multidisciplinary (scarfed trailing edge) nozzle divergent flap geometry was conducted at transonic speeds in the NASA Langley 16-Foot Transonic Tunnel. The geometric parameters investigated include nozzle planform, nozzle contouring location (internal and/or external), and nozzle area ratio (area ratio 1.2 and 2.0). Data were acquired over a range of Mach Numbers from 0.6 to 1.2 , angle-of-attack from $0.0^{\circ}$ to $9.6^{\circ}$ and nozzle pressure ratios from 1.0 to 20.0. Results showed that increasing the rate of change internal divergence angle across the width of the nozzle or increasing internal contouring will decrease static, aeropropulsive and thrust removed drag performance regardless of the speed regime. Also, increasing the rate of change in boattail angle across the width of the nozzle or increasing external contouring will provide the lowest thrust removed drag. Scarfing of the nozzle trailing edges reduces the aeropropulsive performance for the most part and adversely affects the nozzle plume shape at higher nozzle pressure ratios thus increasing the thrust removed drag. The effects of contouring were primary in nature and the effects of planform were secondary in nature. Larger losses occur supersonically than subsonically when scarfing of nozzle trailing edges occurs. The single sawtooth nozzle almost always provided lower thrust removed drag than the double sawtooth nozzles regardless the speed regime. If internal contouring is required, the double sawtooth nozzle planform provides better static and aeropropulsive performance than the single sawtooth nozzle and if no internal contouring is required the single sawtooth provides the highest static and aeropropulsive performance.

\footnotetext{
* Aerospace Engineer, Research Facilities Branch

Copyright (C) 1995 by the American Institute of Aeronautics and Astronautics, Inc. No copyright is asserted in the United States under Title 17, U.S. Code. The U.S. Government has a royalty-free license to exercise all rights under the copyright claimed herein for Governmental purposes. All other rights are reserved by the copyright owner.
}

\section{INTRODUCTION}

Potential future military fighter aircraft will be complex multi-role vehicles with special features designed to counter both enemy air attack and ground defensive action (refs. 1-6). Because of multidisciplinary design issues, nozzle exhaust systems require special shaping in addition to providing high performance (ref. 7). This special shaping usually takes the form of scarfing or angling of nozzle trailing edges. However, scarfing of nozzle trailing edges can affect integrated wind-on performance. Optimizing the nozzle shape to meet many mission requirements, without compromising thrust performance and nozzle boattail drag is the objective of a good nozzle design. Several investigations have looked at the internal performance of nozzles designed to address multidisciplinary issues and have found minimal impact on performance (ref. 8-10), but only a few have looked at the nozzle boattail drag from a parametric view (ref. 11).

Thirteen nozzle configurations were tested on an isolated (no tails or wings) twodimensional body in the NASA Langley 16Foot Transonic Tunnel to determine the effects on aeropropulsive and thrust removed drag performance of various geometric parameters. The geometric parameters investigated include nozzle planform, nozzle contouring location (internal and/or external), and nozzle area ratio (area ratio 1.2 and 2.0). Nozzle pressure ratio was varied from 1.0 to 20.0 , Mach Number was varied from 0.6 to 1.2 , and angle-of-attack was varied from $0^{\circ}$ to $9.6^{\circ}$

\section{$\underline{\text { SYMBOLS }}$}

$A_{e} \quad$ nozzle exit area, in ${ }^{2}$

$A_{e} / A_{t} \quad$ area ratio (see figure 3 )

A, nozzle throat area, in ${ }^{2}$

$\mathrm{C}_{\mathrm{d}-\mathrm{t}}$ thrust removed drag coefficient of afterbody

$\mathrm{C}_{\mathrm{p}, \mathrm{n}} \quad$ External nozzle pressure coefficient, $\left(\mathrm{p}-\mathrm{p}_{\infty}\right) / \mathrm{q}$

$D_{n} \quad$ nozzle drag, $l b f$ 


\begin{tabular}{|c|c|}
\hline $\mathrm{F}_{\mathrm{i}}$ & $\begin{array}{l}\text { measured thrust along body axis, } \\
\text { lbf } \\
\text { ideal isentropic gross thrust, lbf, }\end{array}$ \\
\hline & $R_{\mathrm{i}} \mathrm{T}_{\mathrm{t}, \mathrm{j}} 2 \gamma\left[\mathrm{p}\left(\mathrm{p}_{\mathrm{a}}\right)^{(\gamma-1) \gamma}\right.$ \\
\hline & $\sqrt[W p]{g^{2} \gamma-1}\left[1-\left(\overline{p_{t, j}}\right)\right.$ \\
\hline $\begin{array}{l}\mathrm{F}_{\mathrm{N}} \\
\mathrm{F}_{\mathrm{r}}\end{array}$ & $\begin{array}{l}\text { measured normal force, } \mathrm{lbf} \\
\text { resultant gross thrust, lbf, } \\
\sqrt{\mathrm{F}^{2}+\mathrm{F}_{\mathrm{N}}^{2}+\mathrm{F}_{\mathrm{S}}^{2}}\end{array}$ \\
\hline $\mathrm{F}_{\mathrm{S}}$ & measured side force, $\mathrm{lbf}$ \\
\hline$\pi$ & $\begin{array}{l}\text { acceleration due to gravity, } \\
32.174 \mathrm{ft} / \mathrm{sec}^{2}\end{array}$ \\
\hline $\mathrm{h}_{\mathrm{e}}$ & $\begin{array}{l}\text { average nozzle exit height or height } \\
\text { at } \mathrm{x}=8.25 \mathrm{in} \text {, in (see figure } 3 \text { ), } \\
\left(\mathrm{h}_{\text {side }}+\mathrm{h}_{\text {ti) }}\right) / 2\end{array}$ \\
\hline $\mathrm{h}_{\text {side }}$ & $\begin{array}{l}\text { height of nozzle exit at nozzle } \\
\text { sidewall, in (see figure } 3 \text { ) }\end{array}$ \\
\hline $\mathrm{h}_{\mathrm{t}}$ & $\begin{array}{l}\text { nozzle internal flowpath height } \\
\text { at throat, } h_{t}=0.861 \text { in (see } \\
\text { figure } 3 \text { ) }\end{array}$ \\
\hline$h_{\text {tip }}$ & $\begin{array}{l}\text { height of nozzle exit at nozzle } \\
\text { apex, in (see figure } 3 \text { ) }\end{array}$ \\
\hline $\mathrm{L}$ & $\begin{array}{l}\text { total length of nozzle, in } \\
\text { (see figure } 3 \text { ) }\end{array}$ \\
\hline $\mathrm{L}_{\mathrm{s}}$ & $\begin{array}{l}\text { total length of nozzle from } \\
\text { attachment station to exit at } \\
\text { sidewall, in (see figure } 3 \text { ) }\end{array}$ \\
\hline Mach & Mach Number \\
\hline NPR & nozzle pressure ratio, $\mathrm{p}_{\mathrm{t}, \mathrm{j}} / \mathrm{p}_{\infty}$ \\
\hline $\mathrm{NPR}_{\mathrm{d}}$ & $\begin{array}{l}\text { design nozzle pressure ratio for } \\
\text { fully expanded flow at the nozzle } \\
\text { exit }\end{array}$ \\
\hline $\mathrm{p}$ & local external static pressure, psia \\
\hline $\mathrm{p}_{\mathrm{a}}$ & atmospheric pressure, psia \\
\hline $\mathrm{p}_{\mathrm{t}, \mathrm{j}}$ & average jet total pressure, psia \\
\hline $\mathrm{p}_{\infty}$ & freestream static pressure, psia \\
\hline$q$ & $\begin{array}{l}\text { tunnel freestream dynamic pressure, } \\
\text { psi }\end{array}$ \\
\hline $\begin{array}{l}\mathrm{R}_{\mathrm{j}} \\
\mathrm{T}_{\mathrm{t}, \mathrm{j}}\end{array}$ & $\begin{array}{l}\text { gas constant, } 1716 \mathrm{ft}^{2} / \mathrm{sec}^{2}-{ }^{\circ} \mathrm{R} \\
\text { jet total temperature, }{ }^{\circ} \mathrm{R}\end{array}$ \\
\hline$w_{t}^{t, j}$ & $\begin{array}{l}\text { nozzle internal flowpath width } \\
\text { at throat, } \mathrm{w}_{\mathrm{t}}=4.972 \text { in }\end{array}$ \\
\hline $\mathbf{x}$ & $\begin{array}{l}\text { axial distance measured from the } \\
\text { nozzle connect (positive } \\
\text { downstream), in (see figure } 3 \text { ) }\end{array}$ \\
\hline $\mathrm{y}$ & $\begin{array}{l}\text { lateral dimension measured } \\
\text { from nozzle centerline (positive } \\
\text { toward left wing), in. } \\
\text { (see figure 3) }\end{array}$ \\
\hline $\mathrm{z}$ & $\begin{array}{l}\text { vertical dimension measured from } \\
\text { nozzle centerline (positive down), } \\
\text { in. (see figure } 3 \text { ) }\end{array}$ \\
\hline$\alpha$ & angle of attack, deg \\
\hline
\end{tabular}

$\beta_{\max } \quad$ maximum nozzle boattail angle, deg (see figure 3)

$\beta_{\min } \quad$ minimum nozzle boattail angle, deg (see figure 3)

$\delta_{\max } \quad$ maximum nozzle internal divergence angle, deg (see figure 3)

$\delta_{\min } \quad$ minimum nozzle internal divergence angle, deg (see figure 3)

$\Delta \beta \quad$ total change in boattail angle, deg $\beta_{\max }-\beta_{\min }$

$\Delta \delta \quad$ total change in internal divergence angle, deg $\delta_{\max }-\delta_{\min }$

$\gamma \quad$ ratio of specific heats, 1.3997 for air

$\partial \beta / \partial y \quad$ rate of change in boattail angle across width of the nozzle, deg/in $\left(\delta_{\max }-\delta_{\text {min }}\right) /\left(\left(2 w_{t}\right)\right.$ (\# of sawteeth))

$\partial \delta / \partial y \quad$ rate of change in internal divergence angle across width of the nozzle, deg/in

$\left(\delta_{\max }-\delta_{\min }\right) /\left(\left(2 w_{t}\right)(\#\right.$ of sawteeth $\left.)\right)$

\section{ABBREVIATIONS}

BL butt line

ref. reference

2-D two-dimensional

C-D convergent-divergent

FS fuselage station

$\mathrm{R}$ radius

WL water line

\section{APPARATUS AND PROCEDURES}

\section{Wind Tunnel}

This test was conducted in the NASALangley 16-Foot Transonic Tunnel. A detailed description of the facility is given in reference 12. The tunnel is a single-return atmospheric wind tunnel with a slotted octagonal test section and continuous air exchange. The wind tunnel has a continuously variable airspeed up to a Mach Number of 1.30. Test-section plenum suction is used for speeds above Mach $=1.05$. 


\section{Model and Support System}

A sketch of the sting-strut-supported single-engine simulator with a typical nozzle installed is shown in figure 1 and photographs of a single and double sawtooth nozzle planforms installed in the wind-tunnel are shown in figure 2. The model is an isolated (no vertical or horizontal tails) 2-D fuselage model with a forebody section, a centerbody and a nozzle. The forebody of the model is non-metric (not on the balance) and the centerbody and nozzle are metric (on the balance). The metric break is located at fuselage station 27.000 and the nozzle internal round-to-square transition begins at fuselage station 53.000. The nozzle connect station is at fuselage station 54.486 .

\section{Single-Engine Propulsion System}

An external high-pressure air system provides a continuous flow of clean, dry air at a stagnation temperature of approximately $540^{\circ} \mathrm{R}$ at the nozzle. As shown in figure 1, the pressurized air is transferred from the supply source to the simulator by six air lines that run through the support strut and into a highpressure plenum chamber. The air is then discharged perpendicularly into the model lowpressure plenum through eight multi-holed sonic nozzles equally spaced about the highpressure plenum. The high-pressure plenum is separate from the balance system (nonmetric), but the low-pressure plenum is attached to the balance (metric). This system is designed to minimize axial momentum forces generated by the air as the air passed from the nonmetric high-pressure plenum to the metric lowpressure plenum. Two flexible metal bellows seal the air system between the plenums and compensated for pressurization forces. From the low-pressure plenum, the air passes through a circular choke plate / flow straightener into an instrumentation section and then into the nozzle.

\section{Nozzle Design}

As discussed previously, a parametric investigation was conducted to examine the impact of nozzle planform on the acropropulsive characteristics of isolated 2-D convergent-divergent nozzles. Two baseline planforms $\left(0^{\circ}\right.$ trailing edge angle $)$ and eleven other nozzle configurations (with non-zero trailing edge angles) were investigated.
When the nozzle trailing edge angle changes from being perpendicular to the nozzle centerline $\left(0^{\circ}\right)$, to some angle, there are several methods available to fair the nozzle trailing edge into the afterbody. One method of fairing is continuous curvature (streamwise and spanwise change in curvature) of the nozzle surface (see ref. 11). The method used in the investigation being discussed in this paper involved spanwise fairing of linear segments resulting in a "warped planar surface". The degree of warping depended upon whether the contouring would be accomplished externally, internally, or both internally and externally. The internal contoured configurations force all warping to occur internally resulting in a continuously varying area ratio form the nozzle centerline to the sidewall. The external boattail angle is constant. The external contoured configurations affect only the external boattail, hence the local boattail angle changes with changing butt line. The internal nozzle contour is planar with a constant internal divergence angle. For a given area ratio, the combined internal/external contour case results in both the internal nozzle and external nozzle boattail having warped planar contours resulting in maximum values of local boattail and internal divergence angles which are approximately half of those realized for the other two contouring methods.

Figure 3 shows sketches of the selected planform and contouring geometries with a table of all pertinent dimensions and figure 4 shows three-dimensional sketches of several of the nozzle geometries. The baseline and single sawtooth planforms were tested at two values of area ratio (1.2 and 2.0) and the double sawtooth planforms were tested at only the area ratio 1.2. The single sawtooth nozzles had a single protruding sawtooth on the nozzle divergent flap with the apex of the sawtooth being on the nozzle centerline. The double sawtooth nozzles had two protruding sawteeth with the apexes at $2 \mathrm{y} / \mathrm{w}_{\mathrm{t}}=-0.50$ and 0.50 . Both planforms utilized a $45^{\circ}$ scarf angle. In addition, an externally contoured single sawtooth configurations with a modified "isentropic" internal contour which provided a $0^{\circ}$ divergence angle at the nozzle trailing edge was examined.

Referring to figure $3, \mathrm{~L}$ is the overall length of the nozzle and $\mathrm{L}_{\mathrm{S}}$ is the length of the nozzle at the sidewall. For all nozzles tested, 
the median length of the scarf tip was kept constant at 8.25 inches, the baseline nozzle length as shown in figure 3 . Referring to figure 3 again, the external boattail angle and internal divergence angle were held constant for the baseline nozzle or $\beta_{\min }=\beta_{\max }$ and $\delta_{\min }=\delta_{\max }$ where $\beta_{\min }$ is the external boattail angle at the contour peak, $\beta_{\max }$ is the external boattail angle at the contour valley, $\delta_{\text {min }}$ is the internal divergence angle at the contour peak and $\delta_{\max }$ is the internal divergence angle at the contour valley. For the externally contoured nozzles, $\beta_{\min }<\beta_{\max }$ and $\delta_{\min }=\delta_{\max }$. For the combined contour nozzles, $\beta_{\min }<\beta_{\max }$ and $\delta_{\min }<\delta_{\max }$. For the internally contoured nozzles, $\beta_{\text {min }}=$ $\beta_{\max }$ and $\delta_{\min }<\delta_{\max }$.

Also shown in figure 3 are $\Delta \beta, \Delta \delta$, $\partial \beta / \partial y$ and $\partial \delta / \partial y$ for the various configurations tested. $\Delta \beta$ is the total change in external boattail angle across the width of the nozzle. As the planform goes from single to double, $\Delta \beta$ decreases by approximately half, therefore $\Delta \beta$ is a measure in a sense of the change in planform. $\Delta \delta$ is the total change in internal divergence angle across the width of the nozzle. As the planform goes from single to double, $\Delta \delta$ decreases by approximately half. therefore $\Delta \delta$ is another measure of the change in planform. $\partial \beta / \partial y$ is the rate of change in boattail angle across the width of the nozzle. As the amount of external contouring decreases (i.e. the amount of internal contouring is increasing), $\partial \beta / \partial y$ is decreasing. Even though for the single sawtooth external contoured nozzle $\Delta \beta$ is twice as large as the double sawtooth external contoured nozzle, $\partial \beta / \partial y$ is almost the same. Therefore $\partial \beta / \partial y$ is independent of planform and only measures changes in contour location (amount internally or externally). $\partial \delta / \partial y$ is the rate of change in internal divergence angle across the width of the nozzle. As the amount of internal contouring decreases (i.e. the amount of external contouring is increasing), $\partial \delta / \partial y$ is decreasing. Also, $\partial \delta / \partial y$ is somewhat independent of planform as $\partial \beta / \partial y$ was.

\section{Instrumentation}

A six-component strain-gauge balance was used to measure forces and moments on the metric section of the model. The measured weight-flow rate was obtained from a multiplecritical venturi located in the high pressure air system. Total pressure in the jet was measured by a ten-probe rake in the instrumentation section (see fig. 1). The nozzle total pressure was computed as the average of the individual total pressures. An iron-constantan thermocouple positioned aft of the rake plane measured jet total temperature. Total-pressure and venturi static pressure measurements were made with individual pressure transducers. Nozzle static pressures were measured using electronic pressure scanners. Flow visualization information using an oil, kerosene and dry powder paint mixture was acquired.

\section{Data Reduction}

Fifty frames of data, acquired over a 5second sample interval, were averaged for each measured data parameter at each data point. The averaged values were used in all subsequent computations. Each balance component was corrected for model weight tares, balance-component interactions, modelinstalled balance interactions, and model base and internal pressurization effects. The procedure for correcting the balance measurements is documented in references 12 and 13.

Performance results are presented as static thrust ratio, $F / F_{i}$, thrust-minus-nozzle drag ratio, $\left(\mathrm{F}-\mathrm{D}_{\mathrm{n}}\right) / \mathrm{F}_{\mathrm{i}}$ and thrust removed drag coefficient, $\mathrm{C}_{\mathrm{d}-\mathrm{t}}$. The static thrust ratio, $\mathrm{F} / \mathrm{F}_{\mathrm{i}}$, is representative of the axial static thrust efficiency. The ideal thrust, $F_{i}$, is calculated using the nozzle total pressure, total temperature, measured weight flow, and assumes isentropic flow (see Symbols section). The thrust-minus-nozzle drag ratio, $\left(\mathrm{F}-\mathrm{D}_{\mathrm{n}}\right) / \mathrm{F}_{\mathrm{i}}$, is representative of the total installed aeropropulsive efficiency of the nozzle. The thrust removed drag coefficient, $C_{d-t}$, is representative of the external drag with the internal jet effects removed. 
External static pressure data are presented as pressure coefficient, $\mathrm{C}_{\mathrm{p}, \mathrm{n}}=(\mathrm{p}-$ $\left.\mathrm{p}_{\infty}\right) / \mathrm{q}$, and plotted as a function of $\mathrm{x} / \mathrm{L}$, a nondimensional term representative of orifice location. Flow visualization photographs are also included to provide details of flow behavior. Minimal internal static pressure data were acquired, but are not presented herein.

\section{Accuracy}

The calibrated balance instrument accuracy (this is not an uncertainty) is estimated to be $0.26 \%$ of full scale $( \pm 2.08 \mathrm{lbs})$ in axial force and $0.44 \%$ of full scale $( \pm 2.65 \mathrm{lbs})$ in normal force. Based on the model reference cross sectional area (not wing area, so numbers will be an order of magnitude larger than typical airplane drag counts), $A_{m}=42.396$ in. ${ }^{2}$, and the balance accuracy only, the drag coefficient accuracy is \pm 0.0170 at Mach = $0.60, \pm 0.0114$ at Mach $=0.80, \pm 0.0099$ at Mach $=0.90, \pm 0.0095$ at Mach $=0.95$, and \pm 0.0081 at $\mathrm{Mach}=1.20$.

The pressure measurement accuracy of the 150 psi jet total pressure transducers was \pm 0.150 psi. The pressure measurement accuracy of the 2000 psi multiple critical venturi pressure transducers used to calculate mass flow was \pm 2.0 psi. The pressure measurement accuracy of the 5 psi metric break pressure transducers used to correct balance data was \pm 0.005 psi. The electronically scanned pressure modules used to measure the external surface static pressure had an accuracy of \pm 0.015 psi.

\section{RESULTS AND DISCUSSION}

\section{Effect of Contouring Location}

Results showing the effects of contouring location on the static performance are shown in figure 5. The aeropropulsive performance results are presented in figures 6 and 7 for Mach $=0.80$ and Mach $=1.20$, respectively and the thrust removed drag performance is presented in figures 8 and 9 for Mach $=0.80$ and Mach $=1.20$, respectively. The effects of the rate of change in internal divergence angle, $\partial \delta / \partial y$, and rate of change in boattail angle, $\partial \beta / \partial y$, on static, aeropropulsive and thrust removed drag performance for both the single and double sawtooth nozzles (no baseline nozzles) are presented in figure 10 for static conditions at NPR $=2.0,3.9 \& 10.0$, in figure 11 for Mach $=0.8$ and $\alpha=0.0^{\circ}$ at NPR $=2.0,3.9 \& 10.0$ and in figure 12 for Mach $=$ 1.2 and $\alpha=0.0^{\circ}$ at NPR $=8.0 \& 10.0$. The effects of contouring location on external pressure at the nozzle sidewall centerline, divergent flap edge and divergent flap centerline are shown in figures 13 and 14 for $\mathrm{Mach}=0.80$ at NPR $=3.9$ and $\mathrm{Mach}=1.20$ at NPR $=10.0$ respectively. Data are compared with the unscarfed baseline nozzle for the area ratio 1.2 nozzle.

Static Performance- In figure 5 it can be seen that the internally contoured nozzles have the lowest static performance. In figure 10 it is shown that the static performance decreases with increasing rate of change in internal divergence angle, $\partial \delta / \partial y$, regardless of the nozzle pressure ratio. As discussed earlier, the rate of change in internal divergence angle is nearly directly proportional to the amount of internal contouring. Also in figure 10 it can be seen that increasing the rate change in the boattail angle, $\partial \beta / \partial y$, increases performance. Since external contouring does not directly affect static performance, the effect of increasing performance with $\partial \beta / \partial y$ is simply due to the fact that increasing external contouring decreases internal contouring required for a given nozzle configuration. The nozzle with the highest rate of change in boattail angle has the lowest rate of change in internal divergence angle and hence the highest static performance. It can be concluded that increasing the rate of change in internal divergence angle or increasing internal contouring will decrease static performance.

Wind-On Performance- In figure 6 for Mach $=0.8$ it can be seen that increasing the amount of internal contouring decreases aeropropulsive performance for the single and double sawtooth nozzles. The results are similar in figure 7 for the supersonic condition at Mach $=1.2$. The baseline nozzle had the highest overall performance, other than the single sawtooth externally contoured nozzle in the subsonic regime, thus indicating the 
scarfing of nozzle trailing edges reduces aeropropulsive performance for the most part. In figures 8 and 9 it is shown that increasing the amount of internal contouring decreases the thrust removed drag performance. The baseline nozzle had substantially lower thrust removed drag at the higher nozzle pressure ratios, thus indicating that nozzle scarfing increases external drag. For NPR $<4$, the single sawtooth nozzles had lower drag than the baseline nozzle subsonically however. The design nozzle pressure ratio is $\mathrm{NPR}_{d}=3.86$ for the $A_{e} / A_{t}=1.2$. In addition, the externally contoured single sawtooth nozzle had lower thrust removed drag than any of the scarfed nozzles, but not lower than the baseline. This is probably the reason that the single sawtooth externally contoured nozzle had higher aeropropulsive performance than the baseline nozzle because the more dominate internal losses for the externally contoured single sawtooth nozzle were less than the baseline nozzle as indicated in figure 5, thus making up for the increase in drag of the single sawtooth externally contoured nozzle. Also it can be seen in figures 9 and 10 that larger losses occur supersonically than subsonically when nozzle scarfing is done. Furthermore it can be seen that the thrust removed drag decreases much faster for the baseline nozzles than the scarfed nozzles with increasing NPR thus indicating that the plume shape for the scarfed nozzles adversely affects the performance when compared to the baseline nozzle, especially at the higher nozzle pressure ratios. In figures 11 and 12 it is shown that increasing the rate of change in internal angle decreases aeropropulsive performance as it did statically. Also, it can be seen that increasing the rate of change in external boattail angle increases aeropropulsive performance. The fact that the wind-on effects do not change from the static effects would indicate that the internal geometry changes affect performance more than external geometry changes. The effects of rate of change in boattail angle on thrust removed drag are not as clear. Overall it appears that increasing $\partial \beta / \partial y$ decreases external drag. This would indicate that larger amounts of external contouring for a scarfed nozzle provides the lowest external drag.

External Pressure Results- Static pressure coefficient data on the nozzle boattail are presented in figures 13 and 14 for Mach = 0.8 at $\mathrm{NPR}=3.9$ and $\mathrm{Mach}=1.2$ at $\mathrm{NPR}=$
10.0 , respectively. The nozzle pressure ratios chosen were meant to be somewhat indicative of actual throttle settings at the given Mach number. The subsonic data (figure 13) all show a large expansion region just downstream of the nozzle connect station $(\mathrm{x} / \mathrm{L}=0)$ resulting from flow turning over the shoulder. Negative values of $C_{p, n}$ of course result in drag if acting on areas with aft facing projected area, (such as is the case here). Flow then begins to recompress just downstream of the nozzle connect station (and shoulder) and by $\mathrm{x} / \mathrm{L}=0.4$ to 0.5 actually becomes positive, hence has a favorable effect on drag. It is interesting to note that all scarfed nozzle configurations provided higher static pressures than the baseline nozzle configuration. Based on this observation, one would expect external drag to be highest on the baseline at Mach $=0.8$ and NPR $=3.9$. In figure 8 it is seen that at Mach $=0.8$ and NPR $=3.9$ the baseline nozzle had the highest external drag. However for NPR > 4 , the baseline nozzle has lower drag at Mach 0.8 and has lower drag at all NPR's supersonically as seen in figure 9. This would indicate that the pressure trends presented are not necessarily typical at all NPR's and Mach Numbers. On the single sawtooth configuration where boattail angles are largest, it is apparent that contouring had an impact on the recovered static pressure on the aft portion of the nozzle. Static pressures on the nozzle boattail downstream of $\mathrm{x} / \mathrm{L}=0.4$ increased with increasing external contour. The effect of contouring on the double sawtooth pressure distributions was much less pronounced, probably as a result of the generally smaller boattail and internal divergence angles.

The static pressure distributions presented for Mach $=1.2$ and NPR $=10.0$ are shown in figure 14. As seen, the characteristic shape of the distributions are somewhat different than for the subsonic cases. The overexpansion region is farther downstream and the recovery process is considerably delayed. In fact, pressures generally remained negative (unfavorable) over the entire nozzle length. The data indicate that a shock and ensuing separation generally occurred on the nozzle boattail (as indicated by the steep compression resulting from the shock, followed by a "plateau" region of pressure). The baseline nozzle did not have lower pressures than the rest of the configurations over the entire length of the nozzle as it did at Mach 0.8 and NPR =3.9. This matches the 
results in figure 9 where the thrust removed drag for the baseline indicates that it has the lowest drag. This change in pressure results from subsonic to supersonic is most likely just that different NPR's were plotted for the different speeds and not the overall nozzle characteristics since drag for the baseline nozzle decreased much faster with increasing NPR than for the scarfed nozzles.

\section{Effect of Nozzle Planform}

Results showing the effects of nozzle planform on the static performance are shown in figure 15. The aeropropulsive performance results are presented in figures 16 and 17 for Mach $=0.80$ and Mach $=1.20$, respectively and the thrust removed drag performance is presented in figures 18 and 19 for Mach $=0.80$ and Mach $=1.20$, respectively. The effects of the total of change in internal divergence angle, $\Delta \delta$, and total change in boattail angle, $\Delta \beta$, on static, aeropropulsive and thrust removed drag performance for both the single and double sawtooth nozzles (no baseline nozzles) are presented in figure 20 for static conditions at NPR $=2.0,3.9 \& 10.0$, in figure 21 for Mach $=0.8$ and $\alpha=0.0^{\circ}$ at NPR $=2.0,3.9 \& 10.0$ and in figure 22 for $\mathrm{Mach}=1.2$ and $\alpha=0.0^{\circ}$ at NPR $=8.0 \& 10.0$. The effects of nozzle planform on external pressure at the nozzle sidewall centerline, divergent flap edge and divergent flap centerline are shown in figures 23 and 24 for Mach $=0.80$ at NPR $=3.9$ and Mach $=1.20$ at NPR $=10.0$ respectively. Data are compared with the unscarfed baseline nozzle for the area ratio 1.2 nozzle.

Static Performance- The effects of nozzle planform on internal performance are presented in figure 15. As seen, contouring location had a large impact on the impact of planform shape on internal performance and no general conclusions could be drawn. A conclusion could be drawn that planform effects are secondary in nature when compared to contouring effects which are primary in nature. However, it can be noted that as long as any internal contour is required, the double sawtooth planform provided better performance than the single sawtooth planform. Also in figure 20 it can be seen that increasing the total change in internal divergence angle, $\Delta \delta$, decreases the thrust performance and increasing
$\Delta \beta$ increases thrust performance. As stated previously in the nozzle design section, increasing the number of sawteeth decreases $\Delta \delta$ and $\Delta \beta$. This shows empirically why there are conflicting effects of the number of sawteeth based on whether internal $(\Delta \delta)$ or external $(\Delta \beta)$ effects are considered. The only general conclusions that can be drawn is that for internally contoured nozzles, the double sawtooth (or low $\Delta \delta$ ) had higher performance and for the externally contoured nozzles, the single sawtooth (or high $\Delta \beta$ ) had higher performance.

Wind-On Performance- The effects of nozzle planform on aeropropulsive performance are presented in figures 14 and 15. As seen, results are again highly dependent upon contour location. However, it can be noted that as long as any internal contour is required, the double sawtooth planform provided better performance than the single sawtooth planform subsonically as shown in figure 14. Both scarfed planforms had lower performance than the baseline nozzle. Result were significantly different when all of the contouring took place externally. Aeropropulsive performance of the double sawtooth planform was lower than either the baseline nozzle or the single sawtooth planform. At Mach $=1.2$ (fig. 15), the single sawtooth configuration generally provided slightly higher aeropropulsive performance than the double sawtooth regardless of contour method. Performance of the baseline nozzle was higher than either scarfed nozzle planform. Figures 18 and 19 present the effects of planform on the thrust removed drag. As seen, the single sawtooth nozzles almost always had lower thrust removed drag than the double sawtooth nozzle regardless of the speed regime. Supersonically the double sawtooth nozzles had significantly higher drag than the single sawtooth nozzles, especially the internally contoured nozzles. In figures 21 and 22 can be seen the effects of $\Delta \beta$ and $\Delta \delta$ on aeropropulsive and thrust removed drag performance. The trends are similar to the static results for the aeropropulsive performance. In addition for the thrust removed drag performance it can be seen that increasing $\Delta \beta$ decreases thrust removed drag throughout the speed regime, though results are 
not as clear as the aeropropulsive data. This would indicate that increasing the number of sawteeth (decreasing $\Delta \beta$ ) would increase the thrust removed drag as a general trend, though there are exceptions to this rule.

External Pressure Results- The effects of nozzle planform (for various contour locations) on boattail pressure distribution are presented in figures 23 and 24 for Mach $=0.8$ at $\mathrm{NPR}=3.9$ and $\mathrm{Mach}=1.2$ at $\mathrm{NPR}=10.0$, respectively. As seen in figure 23 for subsonic speeds, pressures on the single sawtooth planform tended to be higher than those measured for either the baseline or double sawtooth planforms indicating that from an external drag viewpoint, the single sawtooth planform would be the most favorable. This is the case as indicated in figure 18 for NPR = 3.9 where the single sawtooth had the lowest or equal thrust removed drag. At Mach $=1.2$, the effect of planform was generally more difficult to see, although it does appear as though the single sawtooth static pressure distributions are slightly more favorable then those of the double sawtooth, but still both of them less favorable than the baseline nozzle. In figure 19 it was shown clearly that the baseline nozzle had much lower thrust removed drag at NPR $=10.0$ (actually off of scale shown) than the single and double sawtooth nozzles and the single sawtooth nozzle had lower drag than the double sawtooth nozzle at Mach $=1.2$ thus matching the pressure results.

\section{Flow Visualization}

Oil, kerosene and dry powder paint mixture flow visualization results are shown in figure 21 for $\mathrm{Mach}=0.8, \mathrm{NPR}=3.8$ and $\alpha=$ $0.0^{\circ}$ with $\mathrm{A}_{\mathrm{e}} / \mathrm{A}_{\mathrm{t}}=1.2$ for the single sawtooth internal contour nozzle, single sawtooth external contour nozzle and the double sawtooth external contour nozzle. Flow is leftto-right across the nozzle. The single sawtooth nozzle with internal contouring had a constant external boattail angle of $20.96^{\circ}$. The single sawtooth nozzle with external contouring had external boattail angles that varied from $16.8^{\circ}$ at the nozzle contour peak to $29.7^{\circ}$ at the contour valleys. The double sawtooth nozzle with external contouring had external boattail angles that varied from $18.6^{\circ}$ at the nozzle contour peaks to $24.2^{\circ}$ at the contour valleys. For the constant external boattail angle of the single sawtooth internal contour nozzle, separation occurs in a circular pattern on the nozzle divergent flap with the separation occurring farther upstream at the nozzle centerline than at the nozzle sidewall. Also, recirculation and flow separation occurs on the peak(s) (minimum external boattail angle) of the nozzle contour for both the single and double sawtooth external contour configurations shown. The large differences in boattail angle across the nozzle width for both nozzle configurations most likely cause the transverse flow and recirculation that occurs.

\section{CONCLUSIONS}

The effects of contouring were consistent throughout the speed regime were and the effects of nozzle planform were not consistent between subsonic or supersonic speeds. For this reason great care will be needed to optimize a design that works well in both subsonic and supersonic flight unless only point cruise performance is desired. The main conclusions from the test are as follows:

1) Increasing the rate of change internal divergence angle across the width of the nozzle or increasing internal contouring will decrease static, aeropropulsive and thrust removed drag performance regardless of the speed regime.

2) Increasing the rate of change in boattail angle across the width of the nozzle or increasing external contouring will provide the lowest thrust removed drag.

3) Scarfing of the nozzle trailing edges reduces the aeropropulsive performance for the most part and adversely affects the nozzle plume shape at higher nozzle pressure ratios thus increasing the thrust removed drag.

4) The effects of contouring were primary in nature and the effects of planform were secondary in nature.

5) Larger losses occur supersonically than subsonically when scarfing of nozzle trailing edges occurs.

6) The single sawtooth nozzle almost always provided lower thrust removed drag than the double sawtooth nozzles regardless the speed regime. 
7) If internal contouring is required, the double sawtooth nozzle planform provides better static and aeropropulsive performance than the single sawtooth nozzle and if no internal contouring is required the single sawtooth provides the highest static and aeropropulsive performance.

\section{REFERENCES}

1. Herbst, W. B.: Future Fighter Technologies, Journal of Aircraft, Vol. 17, No. 8, August 1980, pp. 561-566.

2. Dollyhigh, Samuel M.; Foss, Willard E.: The Impact of Technology on Fighter Aircraft Requirements, SAE Technical Paper Series 851841, October 1985.

3. Mace, J., Doane, P.: Integrated Air Vehicle/Propulsion Technology for a MultiRole Fighter - a MCAIR Perspective, AIAA Paper 90-2278, July 1990.

4. Brown, Squire L.; Snyder, Steven P.: Exploration of Concepts for Multi-Role Fighters ,AIAA Paper 90-2276, July 1990.

5. Herrick, Paul W.: Air-to-Ground Attack Fighter Improvements Through Multi-Function Nozzles, SAE Paper 901002, April 1990.

6. Results from NASA Langley Experimental Studies of Multiaxis Thrust Vectoring Nozzles, SAE Technical Paper 881481, October 1988.

7. Brown, Alan C.: Low Observable Propulsion Design, International Symposium on Air Breathing Engines, 10th, Nottingham, England, Sept. 1-6, 1991, Proceedings. Vol. 1 (A91-56101 24-07), Washington DC, AIAA, 1991, pp 54-61.

8. MacLean, M.: Static Internal Performance Tests of Single-Expansion Ramp Nozzle Concepts Designed with LO Considerations, AIAA Paper 93-2429, June 1993.

9. Cler, Daniel L.: Internal Performance of Two Gimballed Nozzle Concepts with MultiAxis Thrust Vectoring and Reduced Observable Design, NASA TP-3464, August 1994, ITAR/U.S. Government and U.S. Government Contractors Only.
10. Cler, Daniel L. and Mason, Mary L.: Static Internal Performance of Three SphericalConvergent-Flap Nozzles with In-Flight Deployable Plugs, NASA TP-3565, U.S. Government and U.S. Government Contractors Only.

11. Asbury, Scott C. and Carlson, John R. : Transonic Aeropropulsive Performance of Advanced Exhaust Nozzles Designed for Reduced Radar Cross-Section Signatures, NASA TP-3505, July 1995, U.S. Government and U.S. Government Contractors Only.

12. Propulsion Aerodynamics Branch Staff: A User's Guide to the Langley 16-Foot Transonic Tunnel Complex, Revision 1, NASA TM102750, September 1990.

13. Mercer, C. E.; et. al.: Data Reduction Formulas for the 16-Foot Transonic Tunnel NASA Langley Research Center, Revision 2, NASA TM-107646, July 1992. 


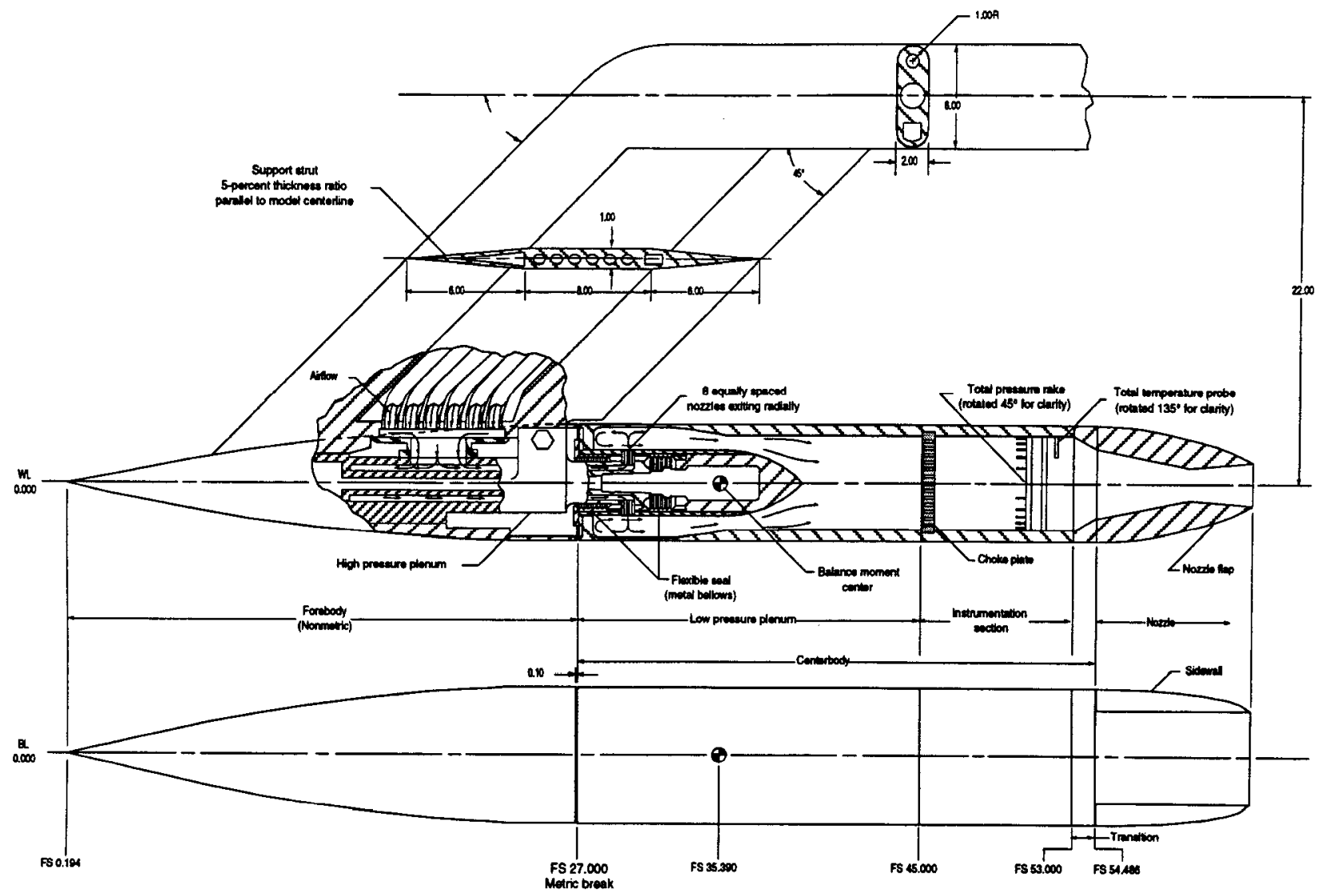

Figure 1. General arrangement of model and support system showing details of the single-engine propulsion simulation system. All dimensions are in inches unless otherwise noted.

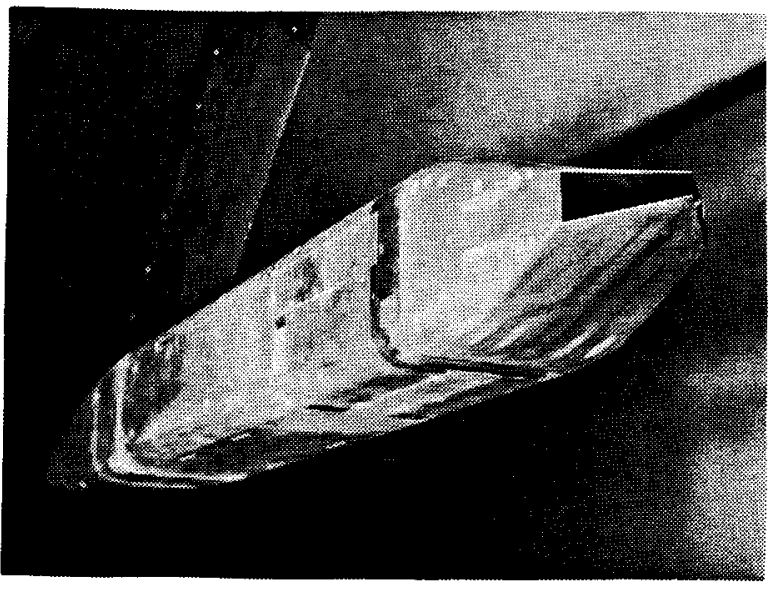

Single sawtooth, combined contour nozzle

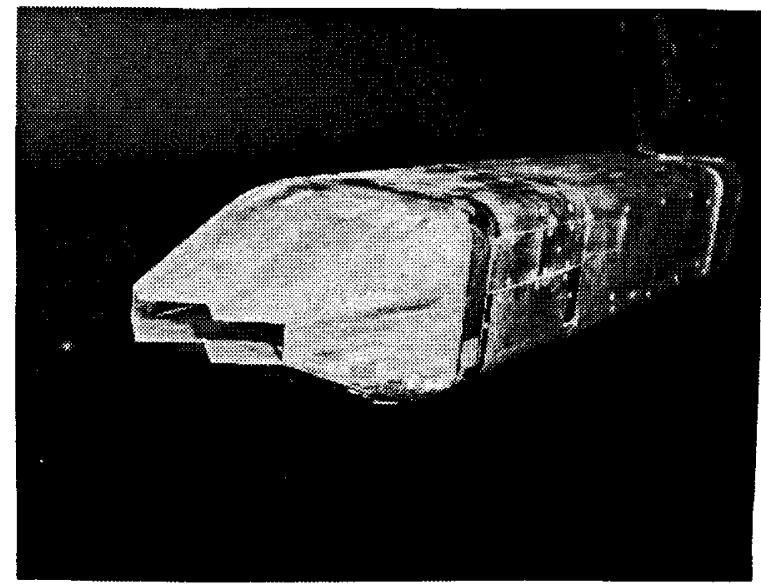

Double sawtooth, external contour nozzle

Figure 2. Photographs of the single-engine propulsion simulation system installed in the tunnel with different nozzle afterbodies installed 

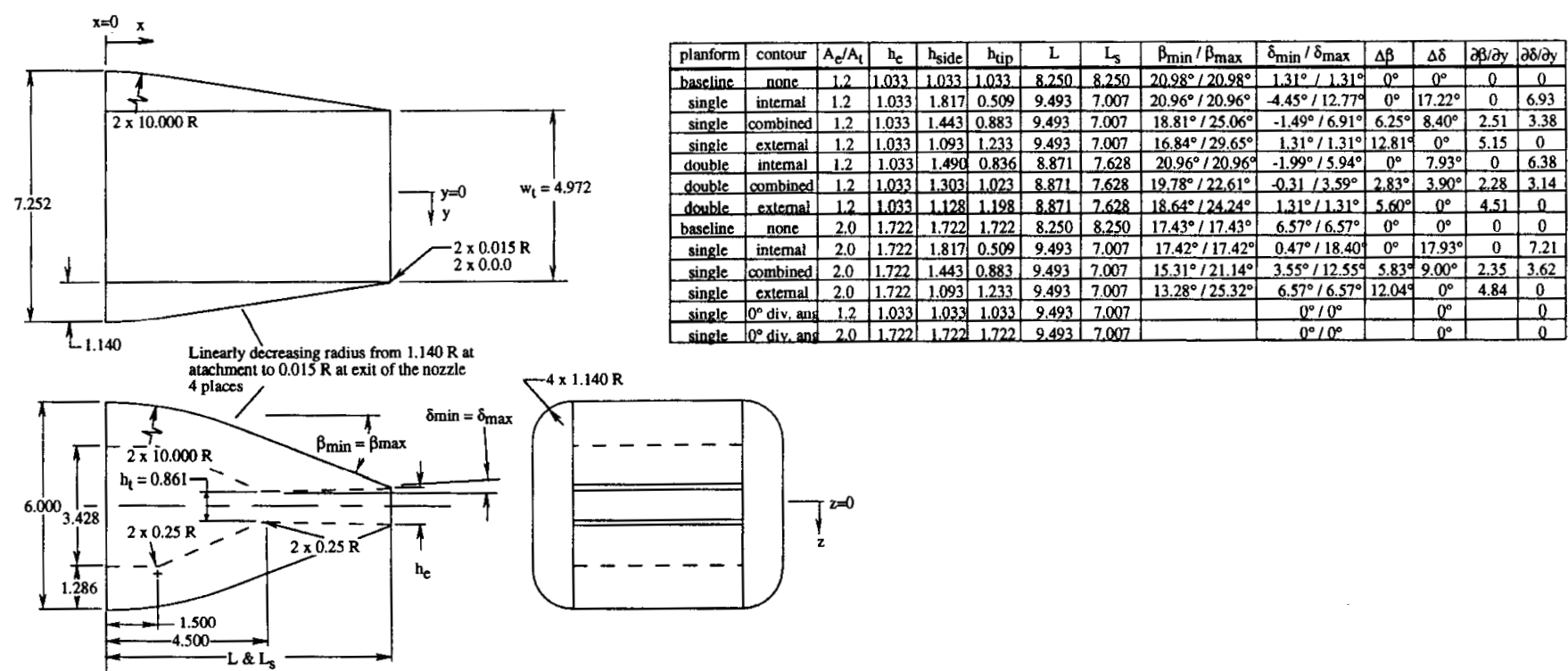

Baseline nozzle with $\mathrm{A}_{\mathrm{e}} / \mathrm{A}_{t}=1.2$
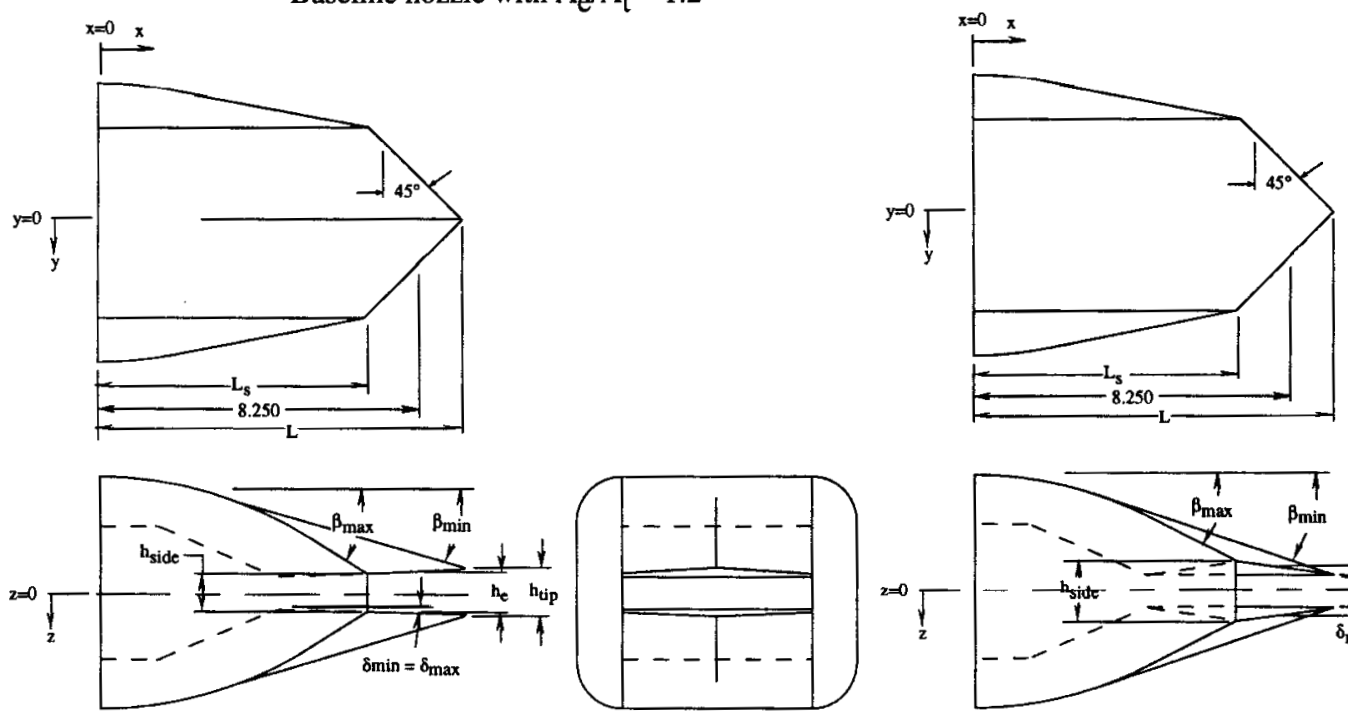

Single sawtooth nozzle with external contouring and $A_{e} / A_{t}=1.2$
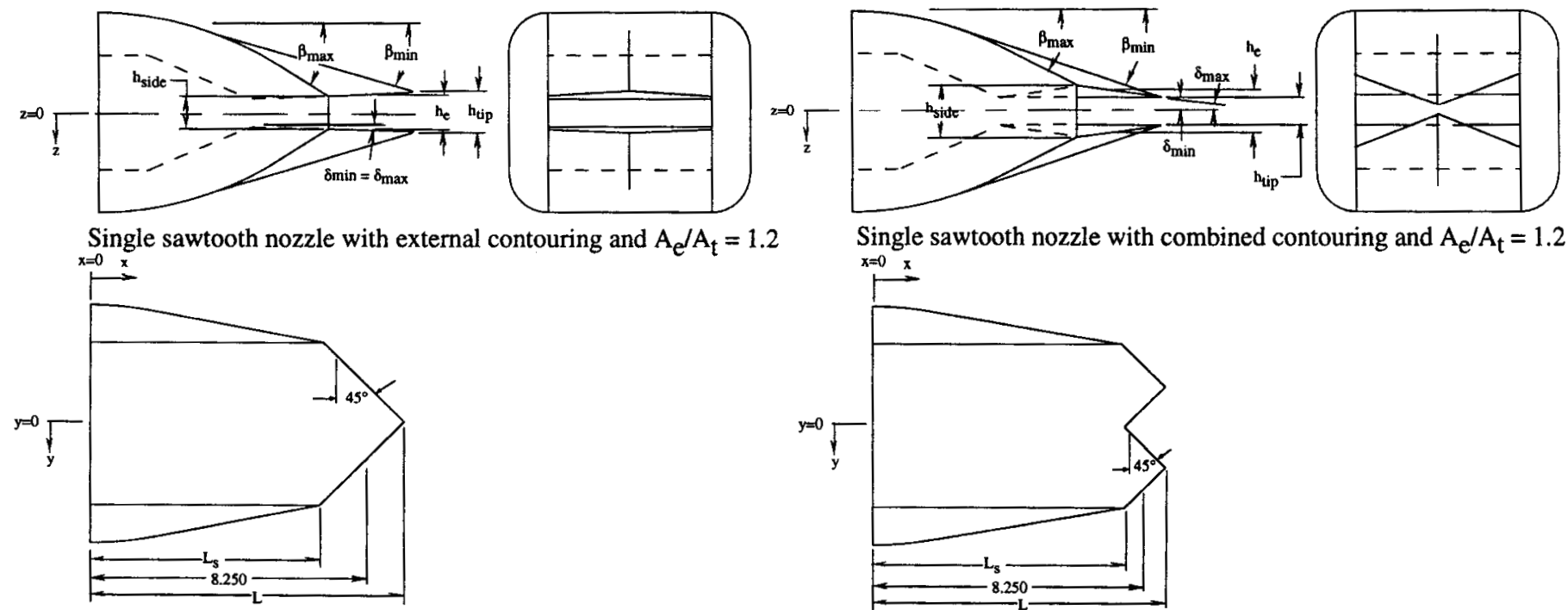

Single sawtooth nozzle with combined contouring and $\mathrm{A}_{\mathrm{e}} / \mathrm{A}_{\mathrm{t}}=1.2$

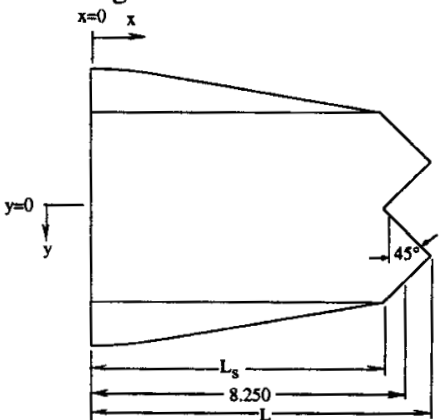

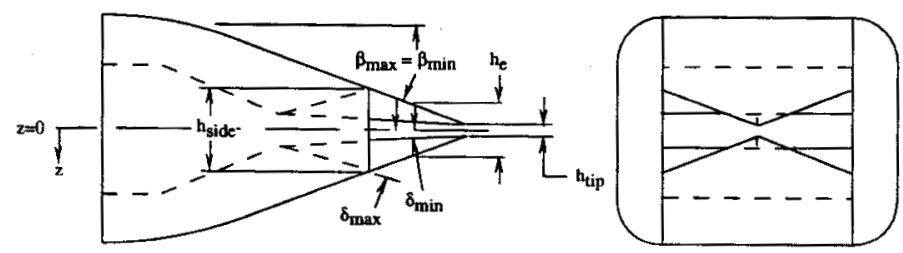

Single sawtooth nozzle with internal contouring and $\mathrm{A}_{\mathrm{e}} / \mathrm{A}_{\mathrm{t}}=1.2$
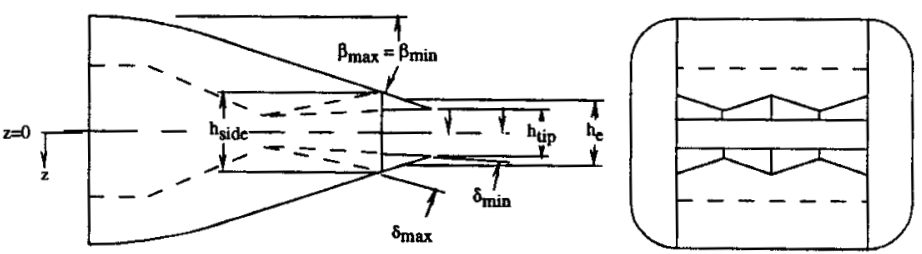

Double sawtooth nozzle with internal contouring and $\mathrm{A}_{\mathrm{e}} / \mathrm{A}_{\mathrm{t}}=1.2$

Figure 3. Sketches of nozzle hardware. All dimensions in inches unless otherwise noted. 


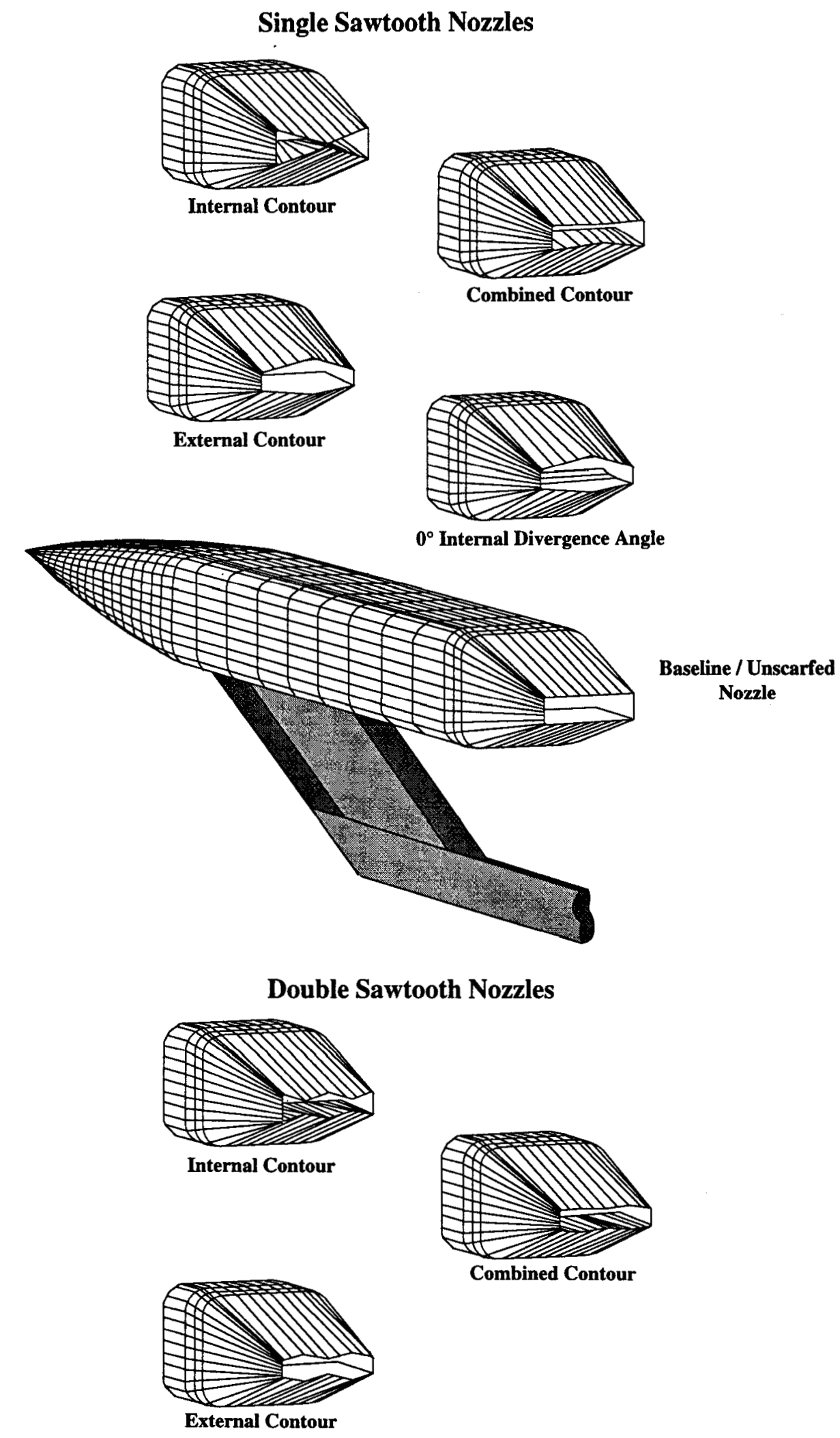

Figure 4. Three-dimensional sketches showing single and double sawtooth planform nozzles with the various contouring methods. 


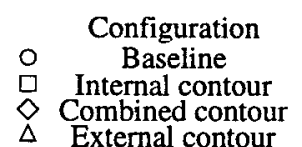

External contour

Single sawtooth

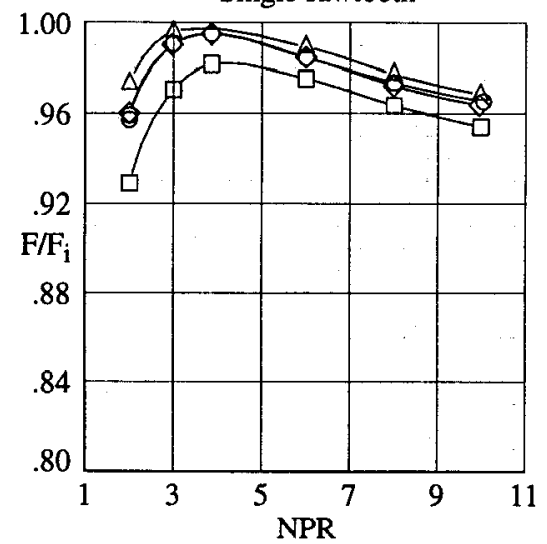

Configuration

$\stackrel{\text { Baseline }}{\circ}$ Internal contour

$\diamond$ Combined contour

$\triangle$ External contour

Double sawtooth

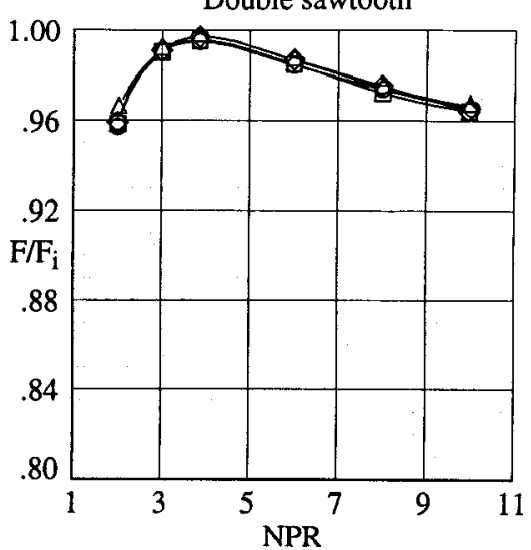

Figure 5. Effect of contouring location on static performance for the $A_{e} / A_{t}=1.2$ nozzle.

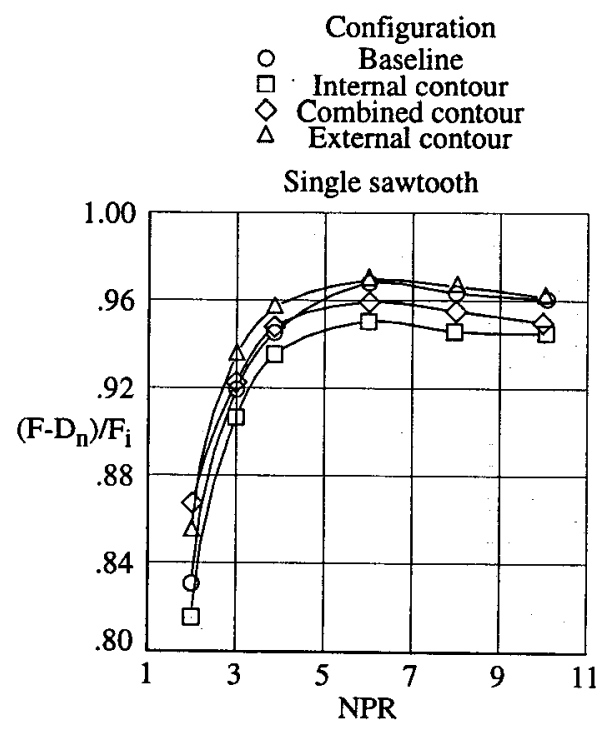

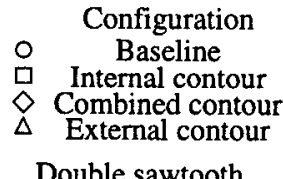

Double sawtooth

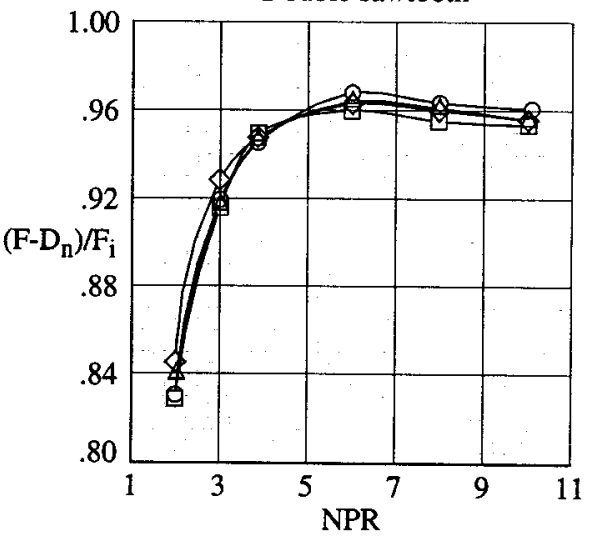
Figure 6. Effect of contouring location on aeropropulsive performance for the $A_{e} / A_{t}=1.2$ nozzle
at Mach $=0.8$ and $\alpha=0.0^{\circ}$.
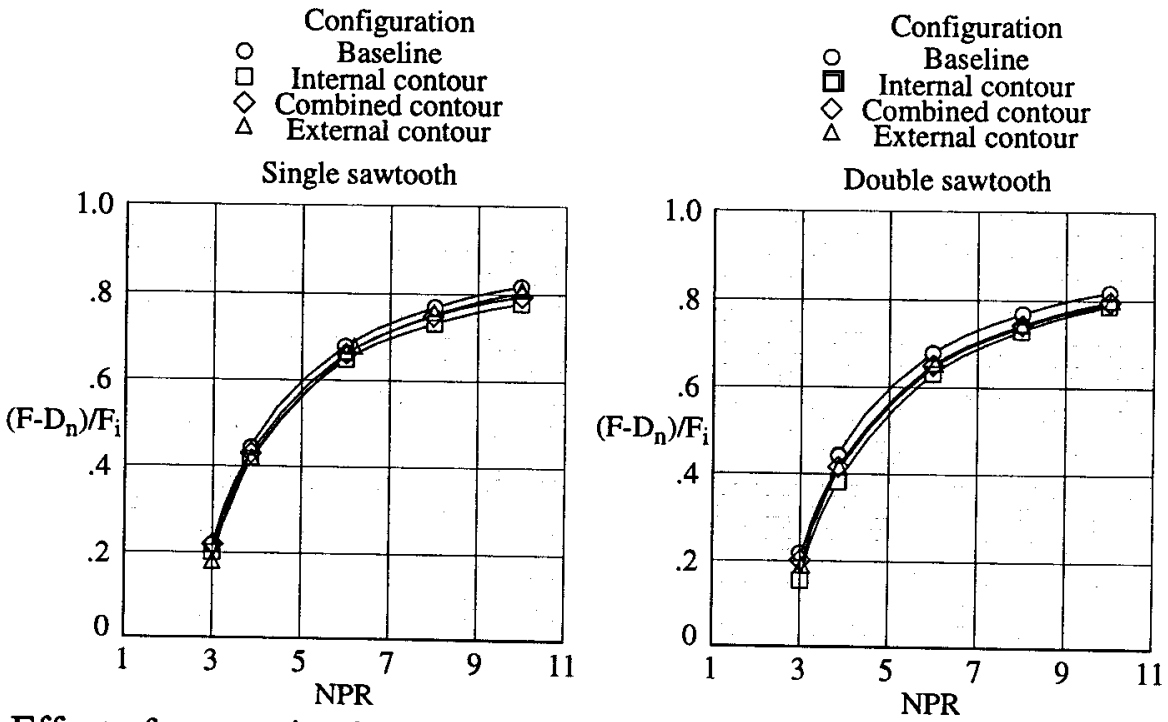
Figure 7. Effect of contouring location on aeropropulsive performance for the $A_{e} / A_{t}=1.2$ nozzle
at Mach $=1.2$ and $\alpha=0.0^{\circ}$. 

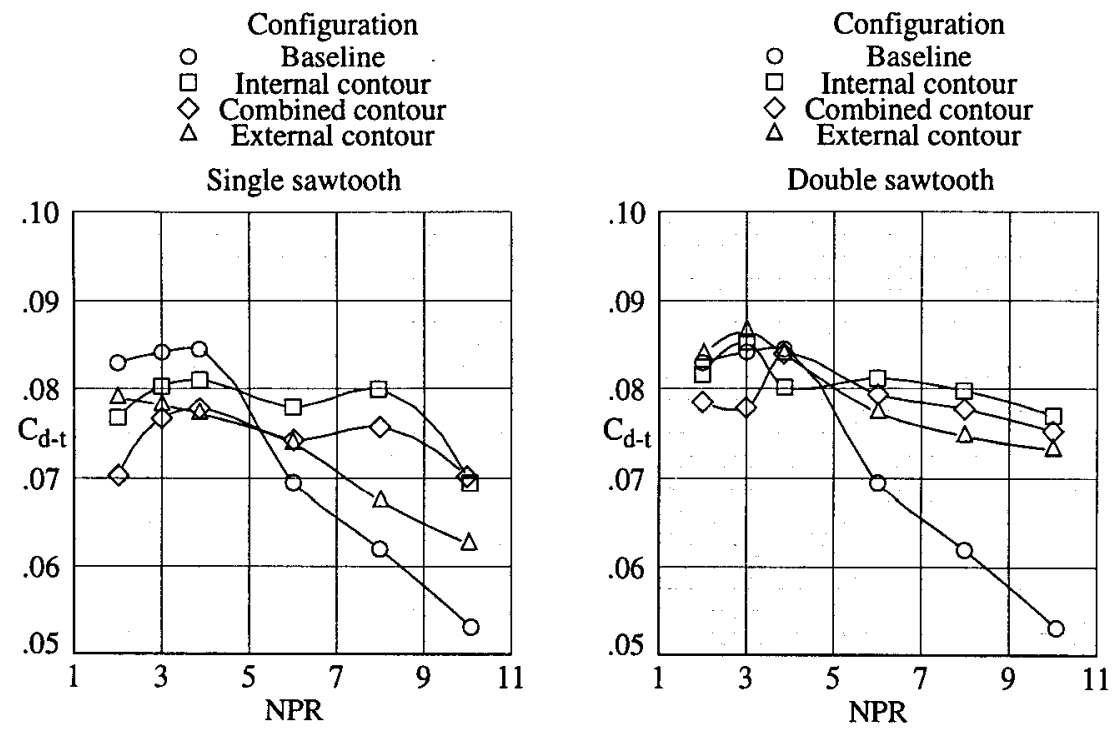

Figure 8. Effect of contouring location on thrust removed drag performance for the $A_{e} / A_{t}=1.2$ nozzle at Mach $=0.8$ and $\alpha=0.0^{\circ}$.

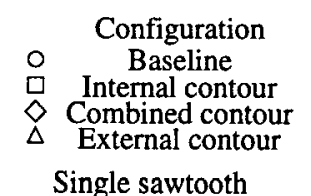

Single sawtooth

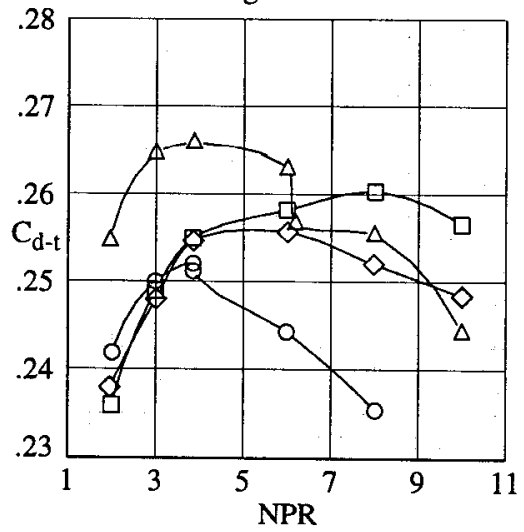

Configuration

Baseline

ㅁ Internal contour

$\diamond$ Combined contour

$\triangle$ External contour

Double sawtooth

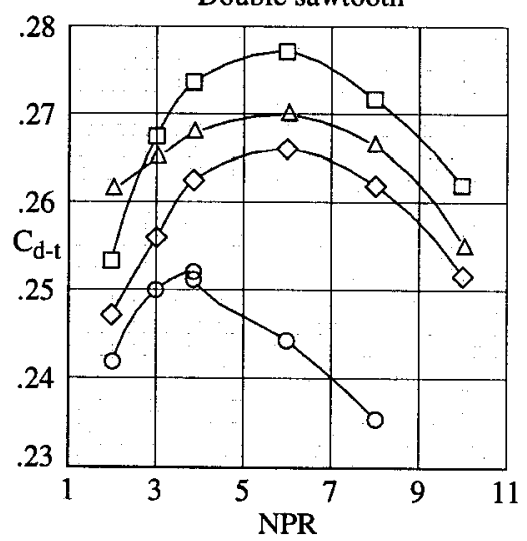

Figure 9. Effect of contouring location on thrust removed drag performance for the $A_{e} / A_{t}=1.2$ nozzle at $\mathrm{Mach}=1.2$ and $\alpha=0.0^{\circ}$. 

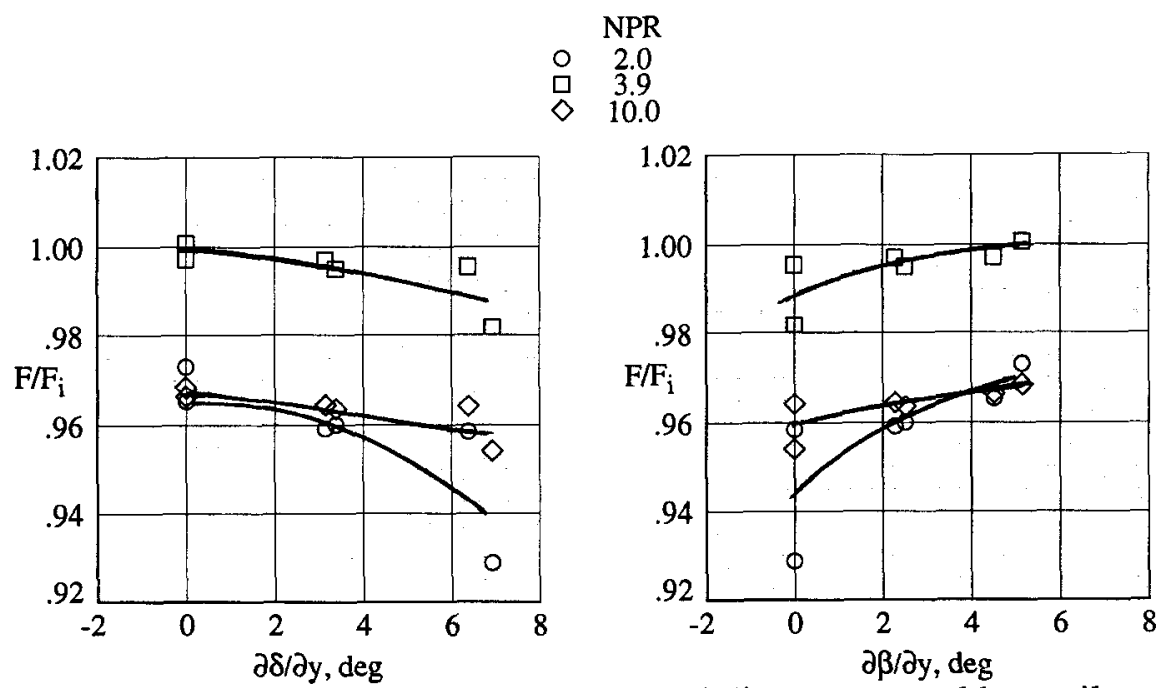

Figure 10. Effect of rate of change in internal divergence and boattail on static performance for the $A_{e} / A_{t}=1.2$ nozzles.
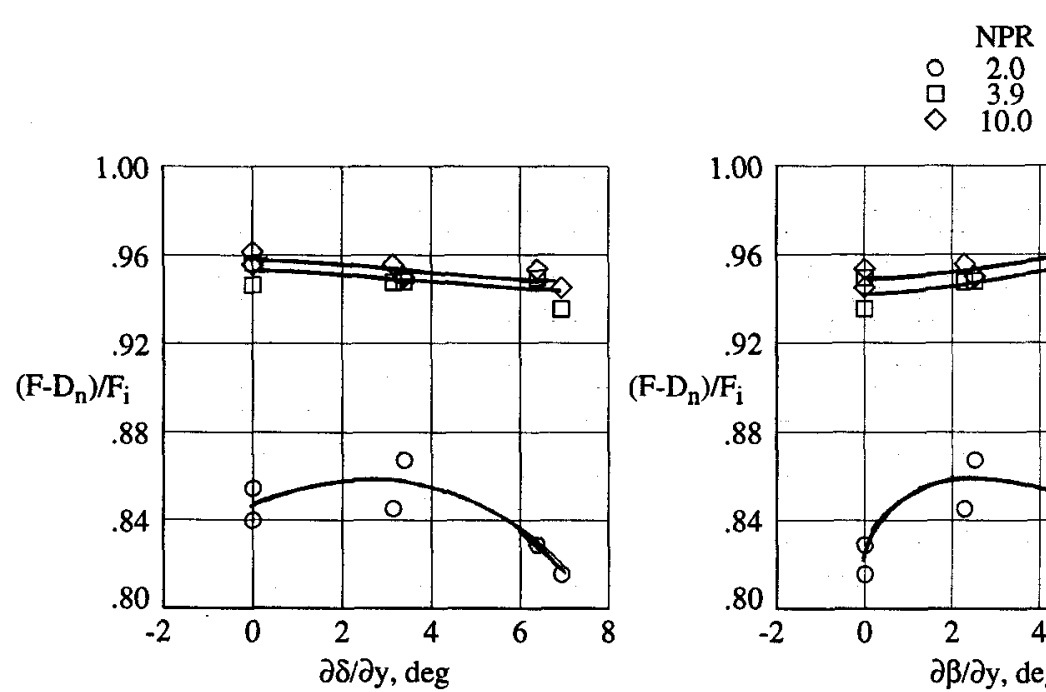

Figure 11. Effect of rate of change in internal divergence and boattail on aeropropulsive and thrust removed drag performance for the $\mathrm{A}_{\mathrm{e}} / \mathrm{A}_{\mathrm{t}}=1.2$ nozzles at Mach $=0.8$ and $\alpha=0.0^{\circ}$
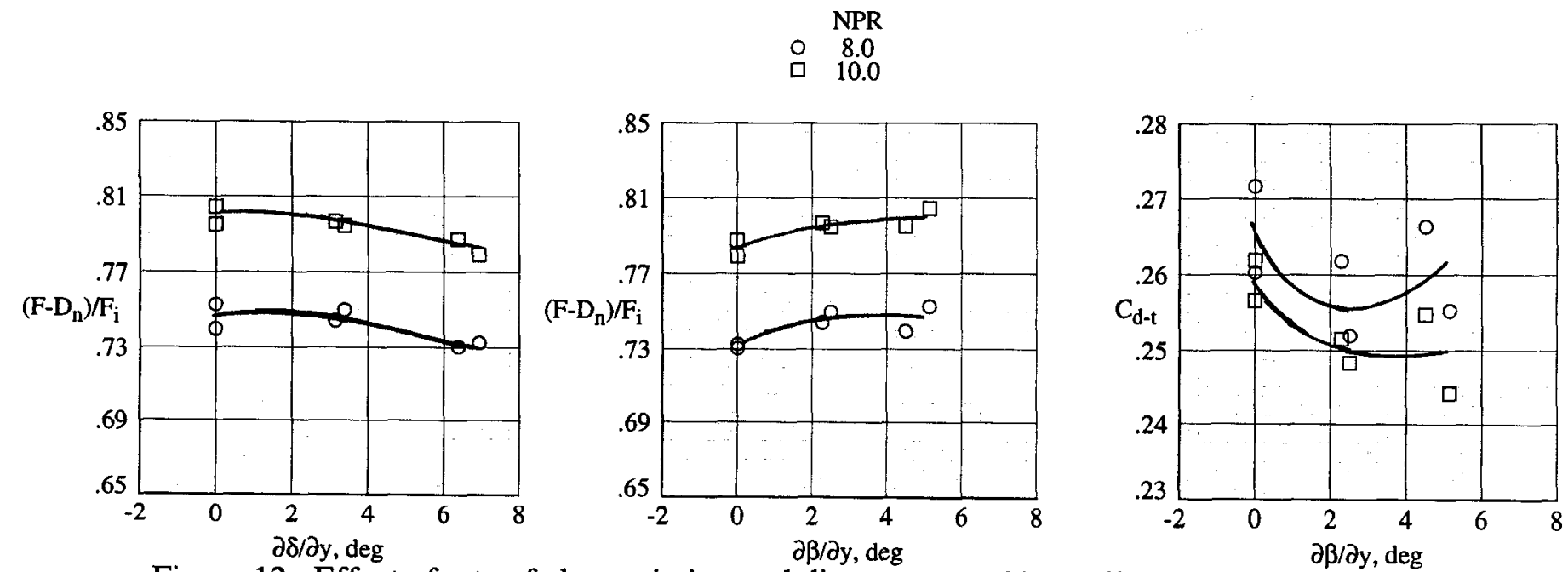

Figure 12. Effect of rate of change in internal divergence and boattail on aeropropulsive and thrust removed drag performance for the $A_{e} / A_{t}=1.2$ nozzles at Mach $=1.2$ and $\alpha=0.0^{\circ}$ 


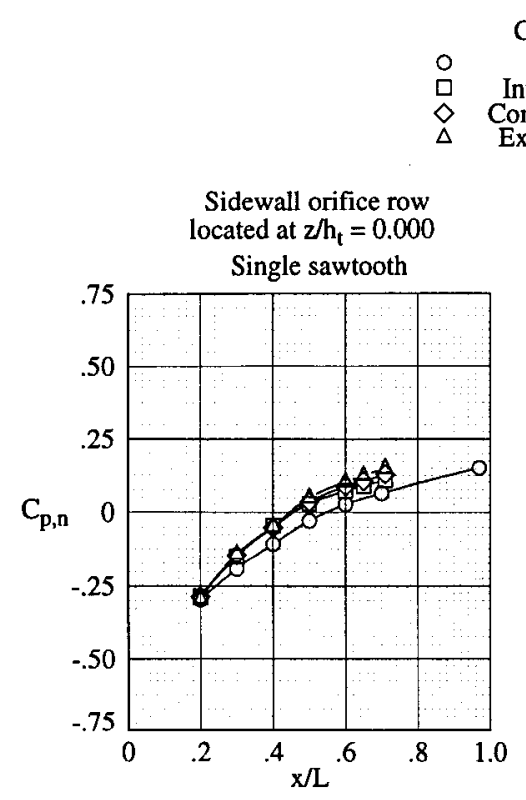

Configuration

Baseline

Internal contour

Combined contour

External contour
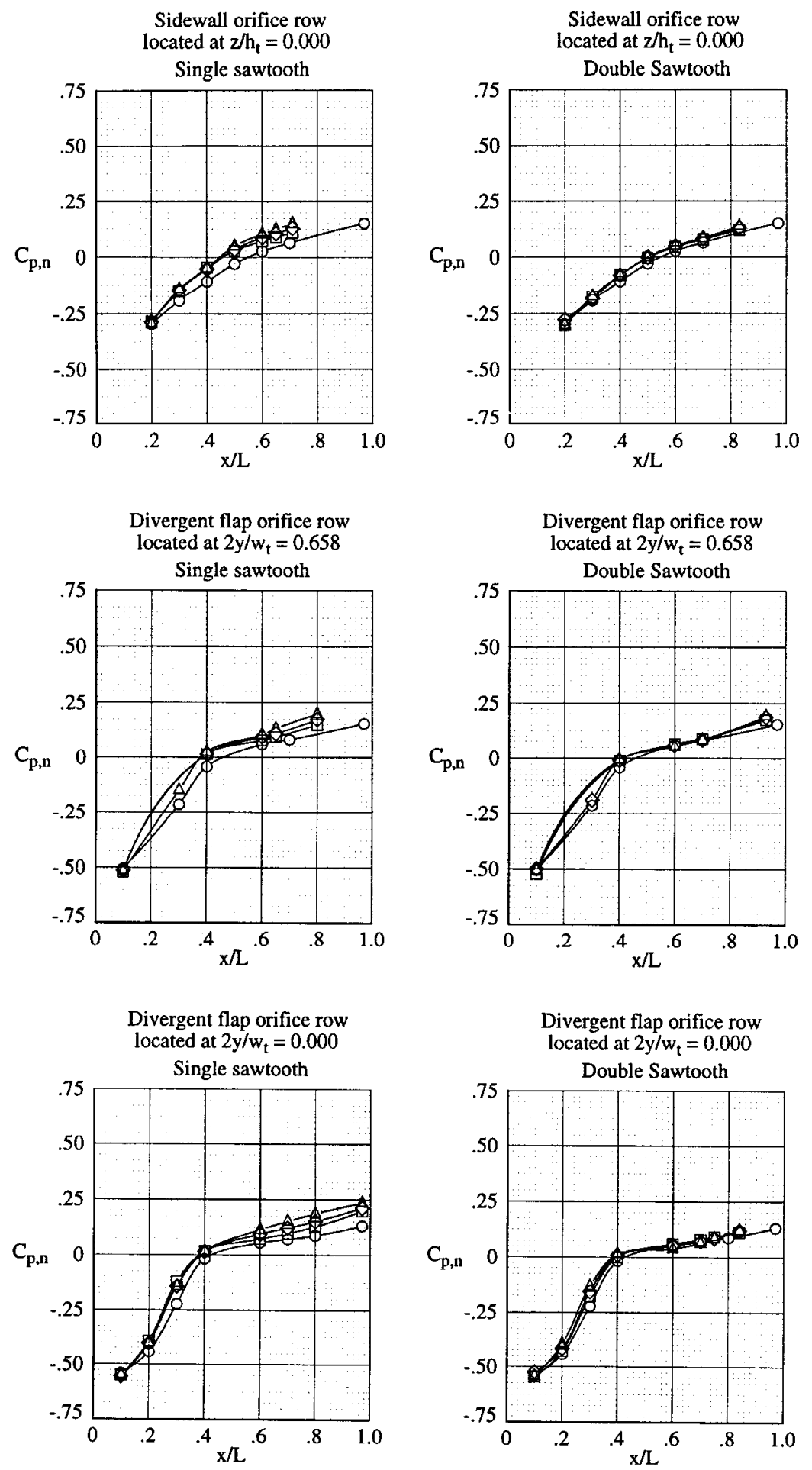

Figure 13. Effect of contour on external static pressures for the $A_{e} / A_{t}=1.2$ nozzle at Mach $=0.8, \alpha=0.0^{\circ}$ and NPR $=3.9$. 


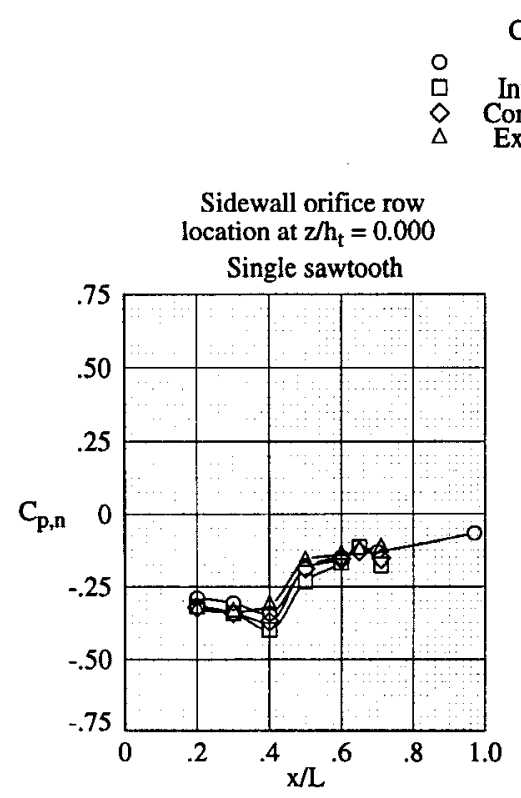

Configuration

Baseline

Internal contour

Combined contour

External contour

Sidewall orifice row ation $\mathrm{z} / \mathrm{h}_{\mathrm{t}}=0.000$
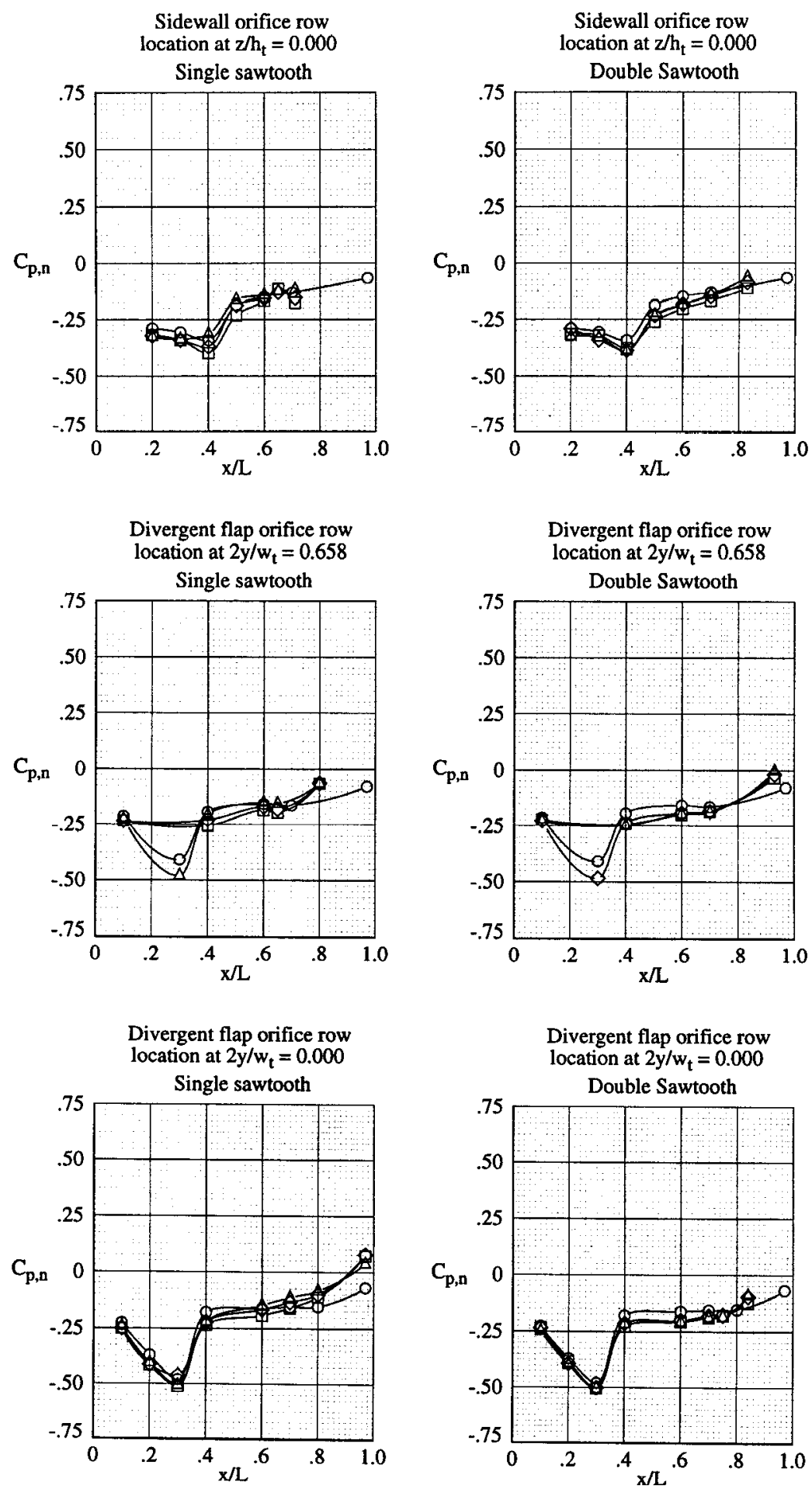

Figure 14. Effect of contour on external static pressures for the $A_{e} / A_{t}=1.2$ nozzle at Mach $=1.2, \alpha=0.0^{\circ}$ and NPR $=10.0$. 


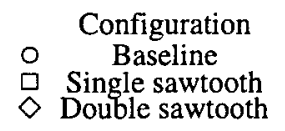

Internal contouring

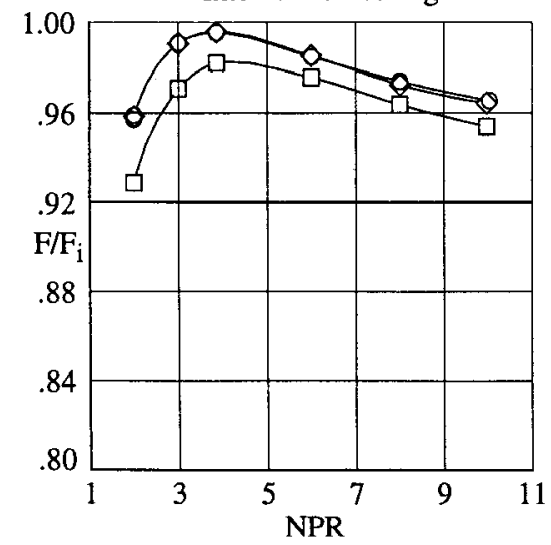

Configuration

- Baseline

Single sawtooth

Double sawtooth

Combined contouring

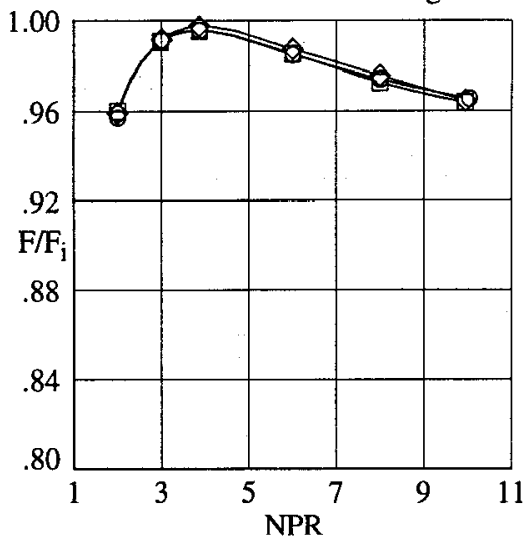

Configuration

- Baseline

Single sawtooth

Double sawtooth

Figure 15. Effect of planform on static performance for the $A_{e} / A_{t}=1.2$ nozzle.

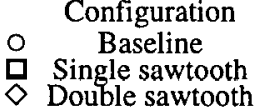

Internal contouring

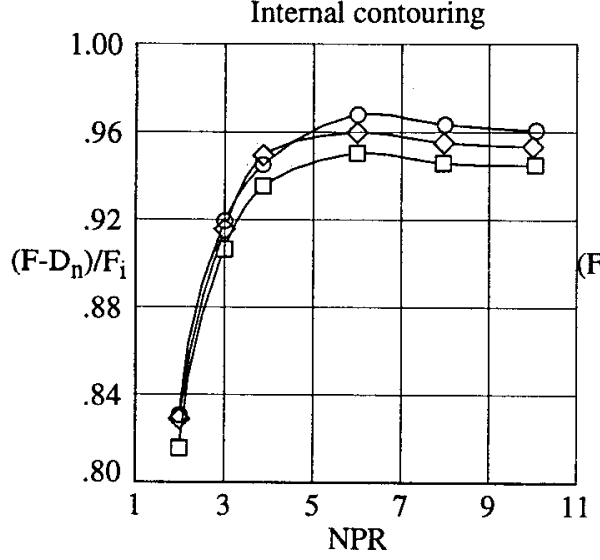

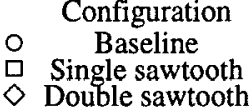

Combined contouring

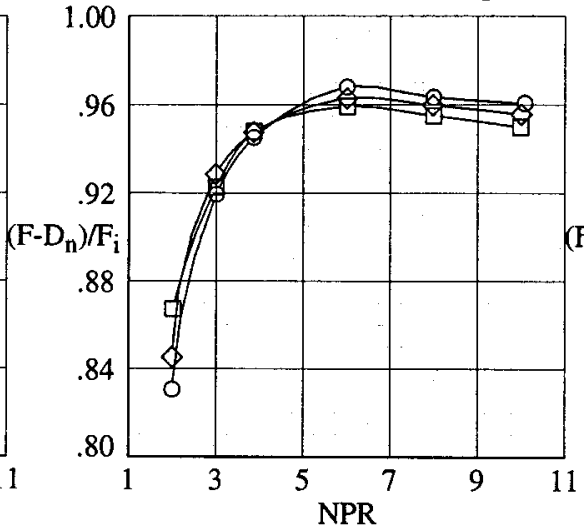

External contouring

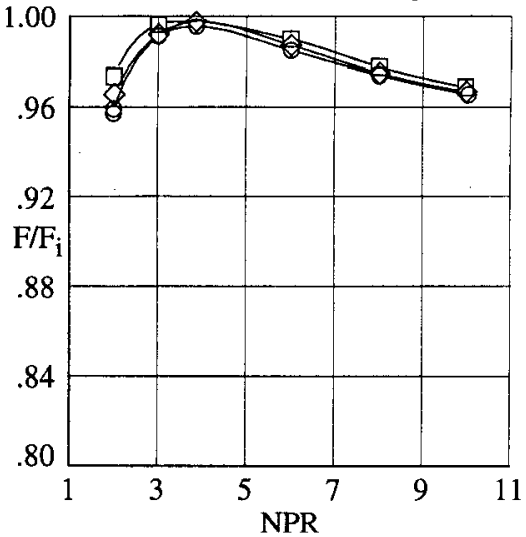

Figure 16. Effect of planform on aeropropulsive performance for the $A_{e} / A_{t}=1.2$ nozzle at Mach $=0.8$ and $\alpha=0.0^{\circ}$.

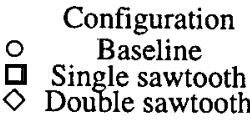

Internal contouring

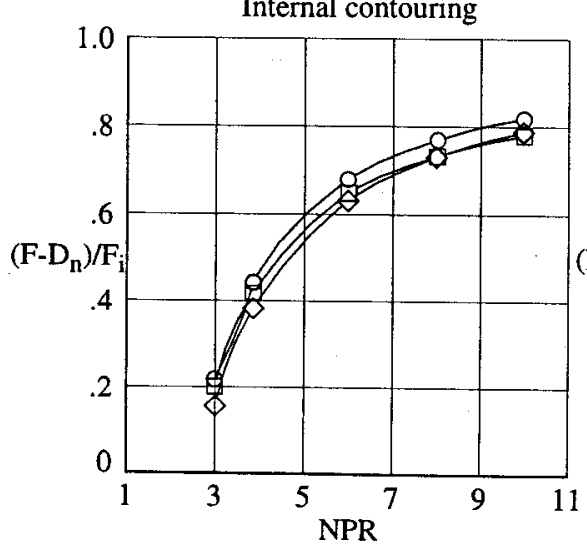

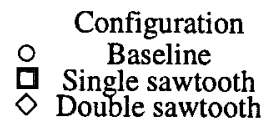

Combined contouring

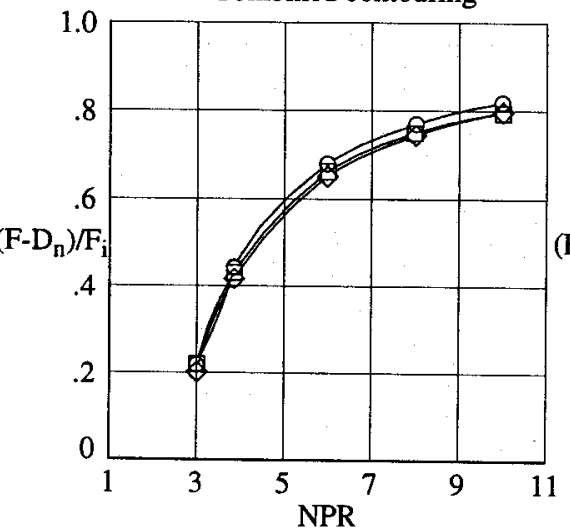

$\stackrel{\text { Configuration }}{\text { Baseline }}$

External contouring

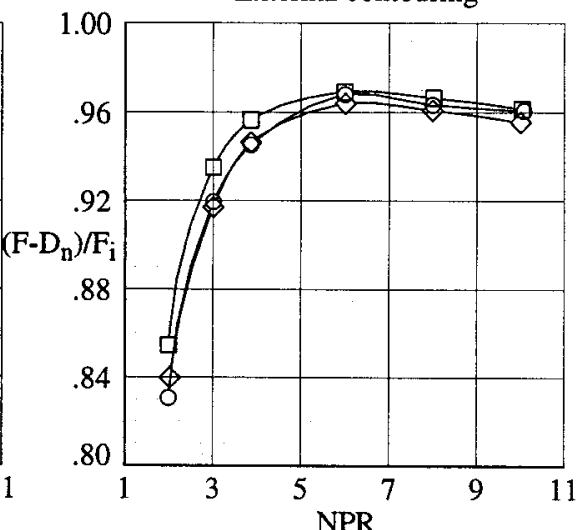

Figure 17. Effect of planform on aeropropulsive performance for the $A_{e} / A_{t}=1.2$ nozzle at $\mathrm{Mach}=1.2$ and $\alpha=0.0^{\circ}$. 

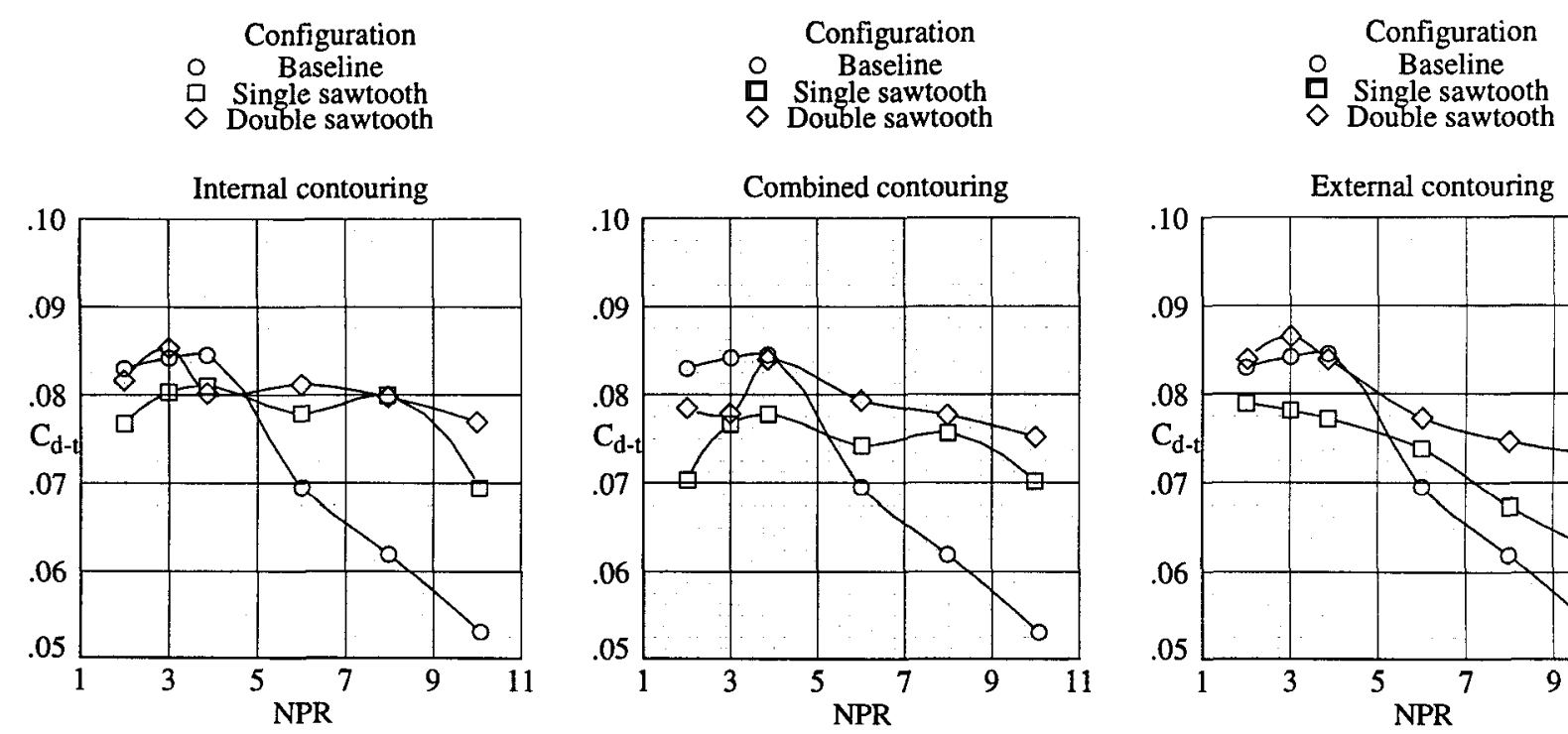

Figure 18. Effect of planform on thrust removed drag performance for the $A_{e} / A_{t}=1.2$ nozzle at Mach $=0.8$ and $\alpha=0.0^{\circ}$.
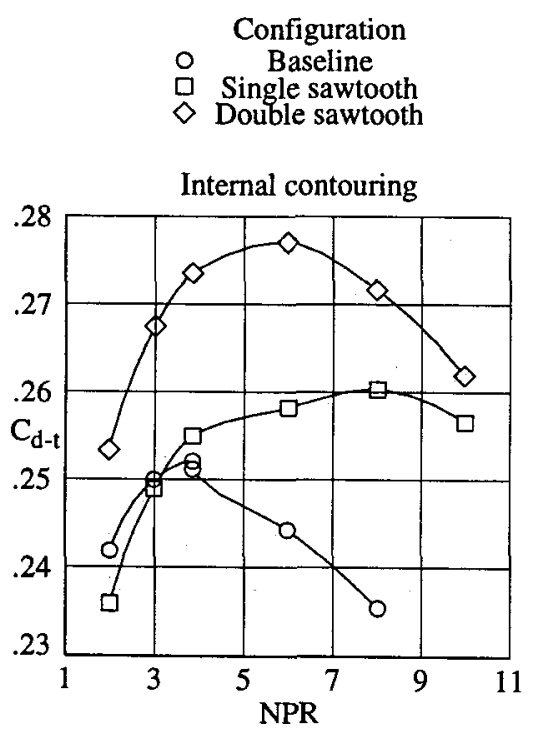
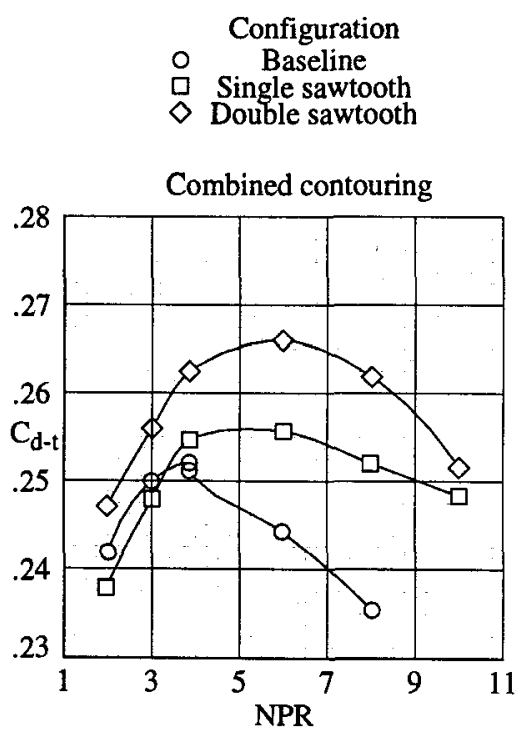

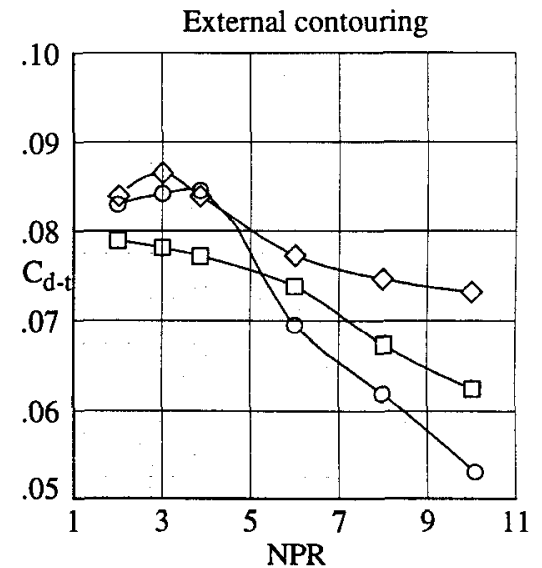

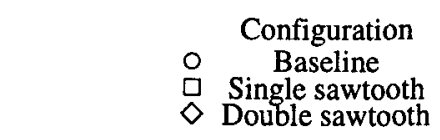

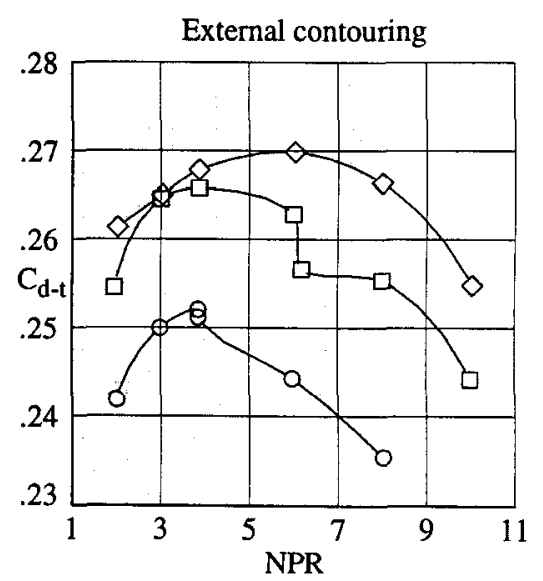

Figure 19. Effect of planform on thrust removed drag performance for the $A_{e} / A_{t}=1.2$ nozzle at Mach $=1.2$ and $\alpha=0.0^{\circ}$. 

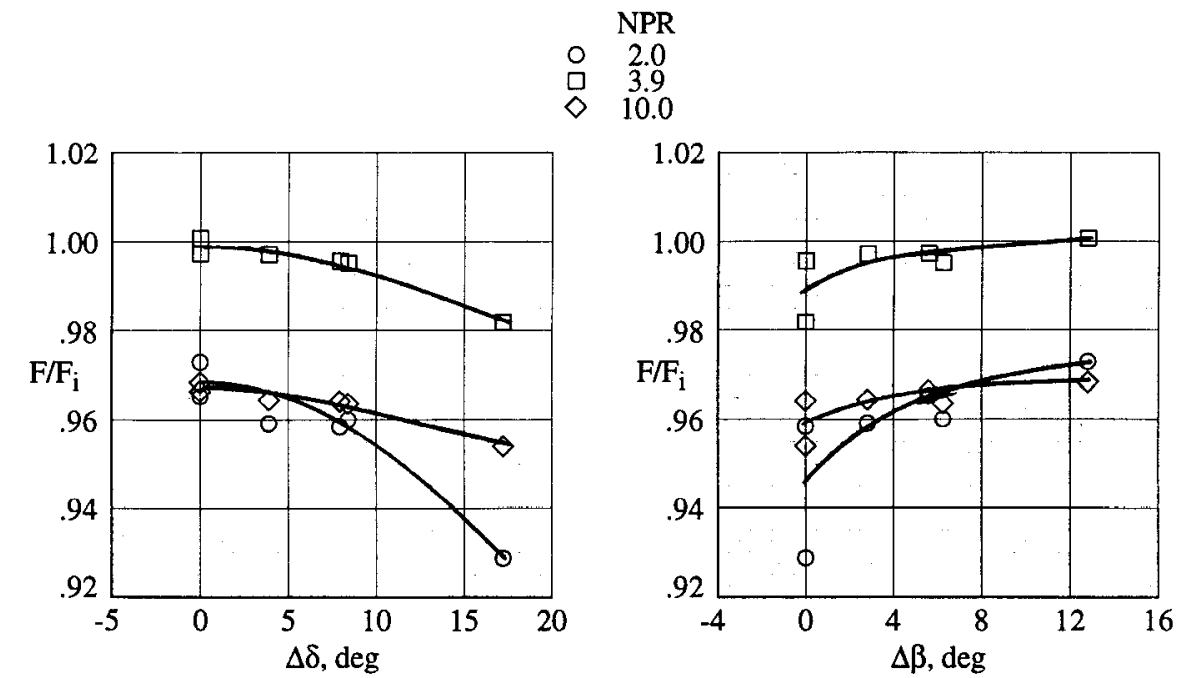

Figure 20. Effect of total change in internal divergence and boattail on static performance for the $A_{e} / A_{t}=1.2$ nozzles.

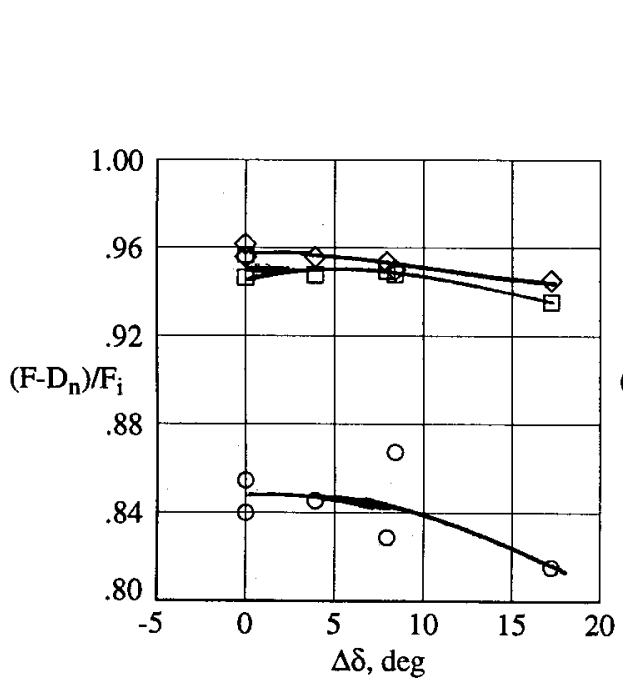

Figure 21. Effect of total change in internal divergence and boattail on aeropropulsive and thrust removed drag performance for the $\mathrm{A}_{\mathrm{e}} / \mathrm{A}_{\mathrm{t}}=1.2$ nozzles at Mach $=0.8$ and $\alpha=0.0^{\circ}$
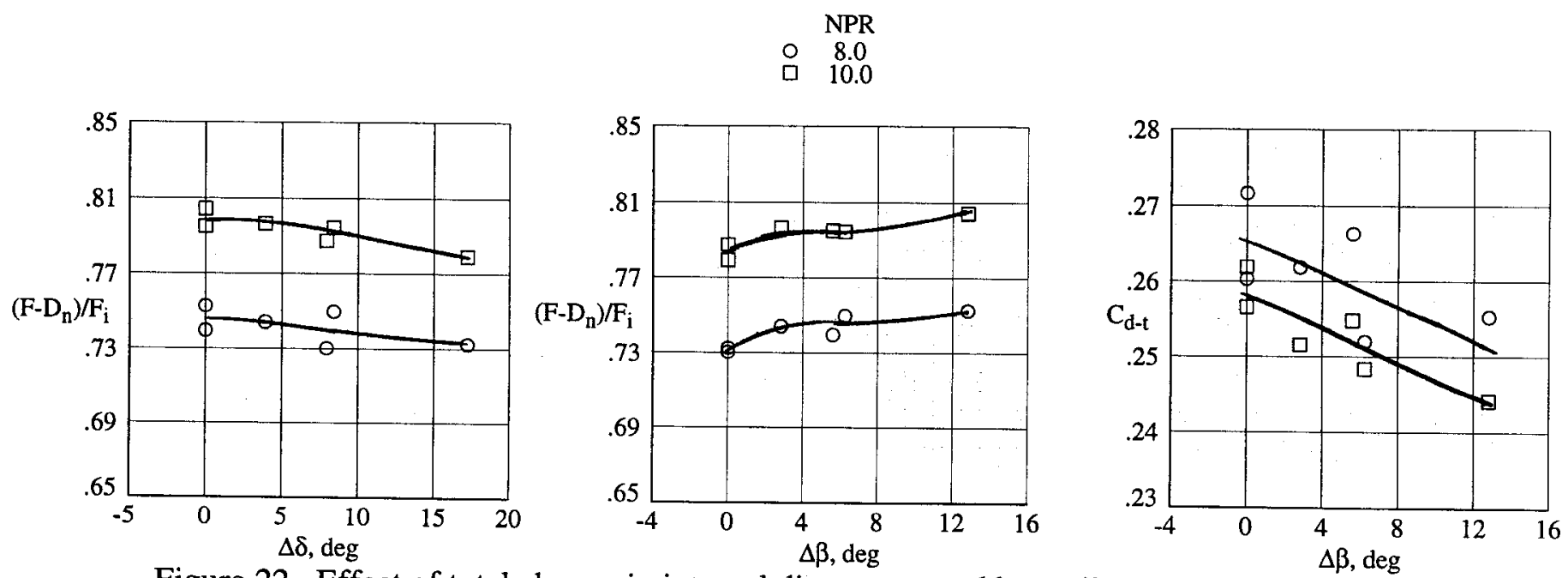

Figure 22. Effect of total change in internal divergence and boattail on aeropropulsive and thrust removed drag performance for the $\mathrm{A}_{\mathrm{e}} / \mathrm{A}_{\mathrm{t}}=1.2$ nozzles at Mach $=1.2$ and $\alpha=0.0^{\circ}$ 

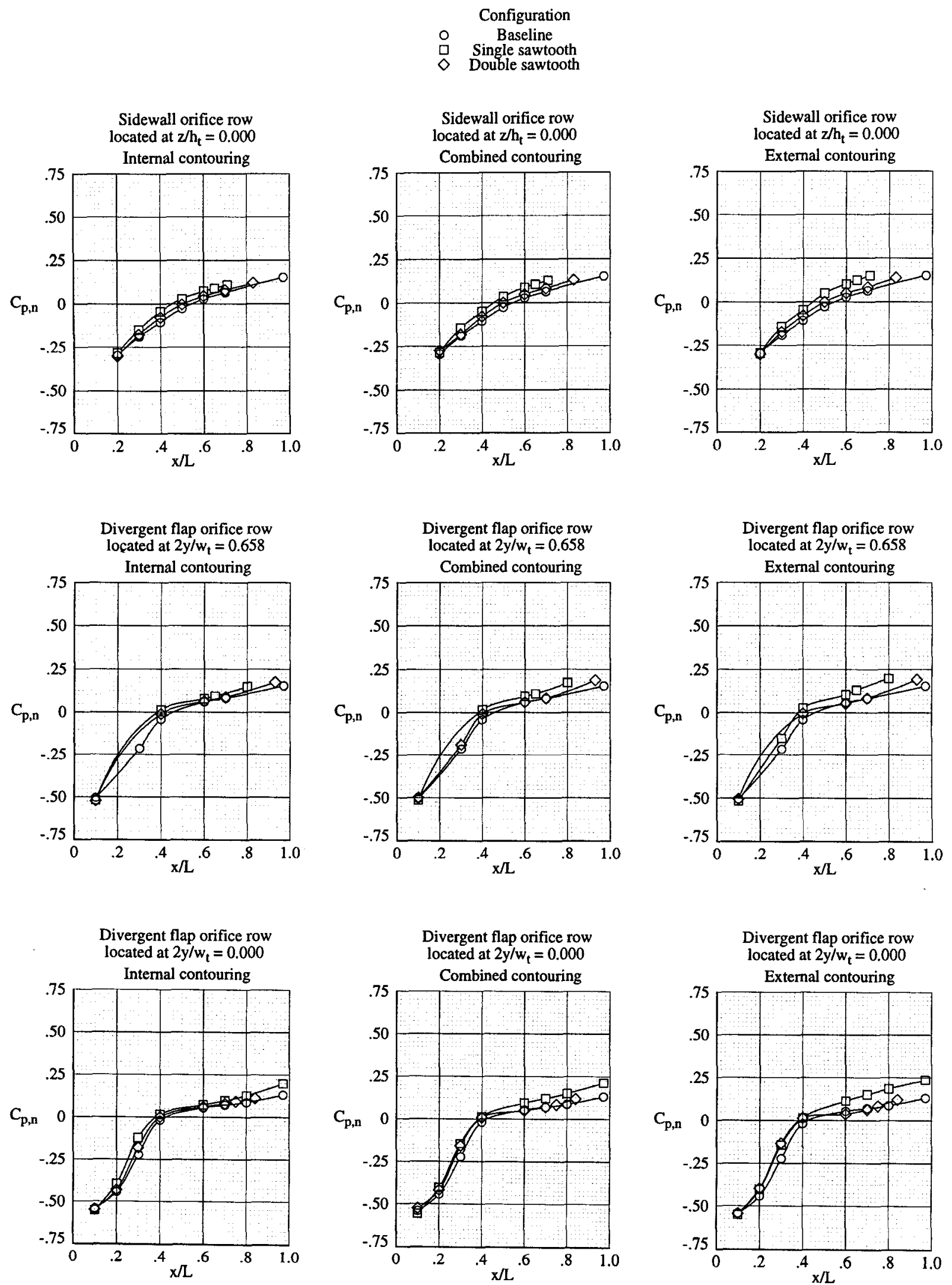

Figure 23. Effect of planform on external static pressures for the $A_{e} / A_{t}=1.2$ nozzle at Mach $=0.8, \alpha=0.0^{\circ}$ and NPR $=3.9$. 

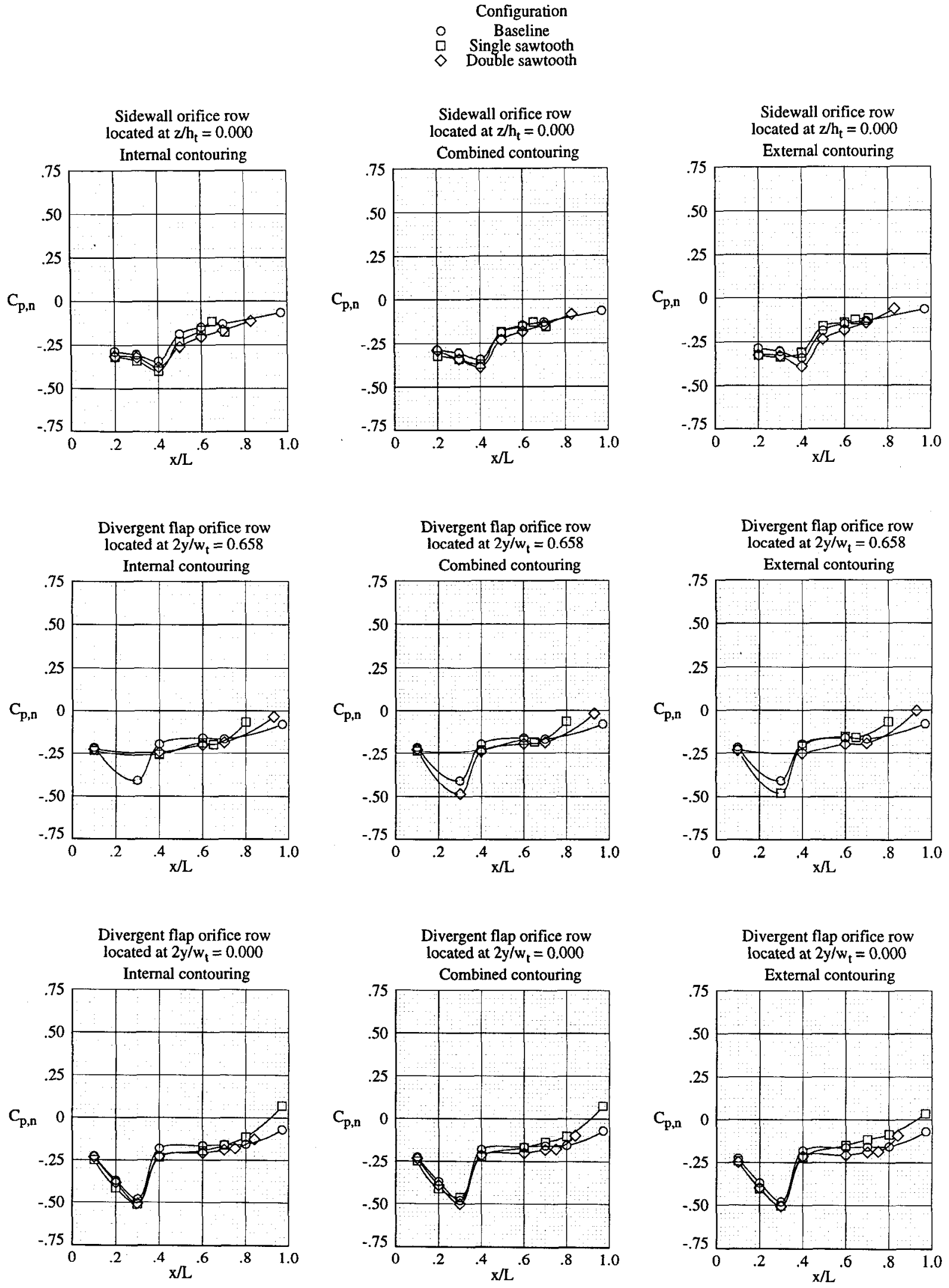

Figure 24. Effect of planform on external static pressures for the $A_{e} / A_{t}=1.2$ nozzle at Mach $=1.2, \alpha=0.0^{\circ}$ and NPR $=10.0$. 


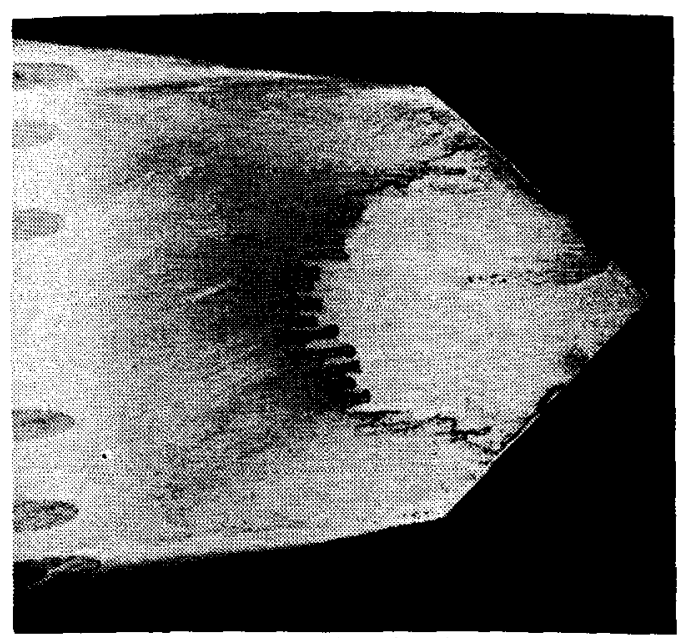

Single sawtooth with internal contouring, top view.

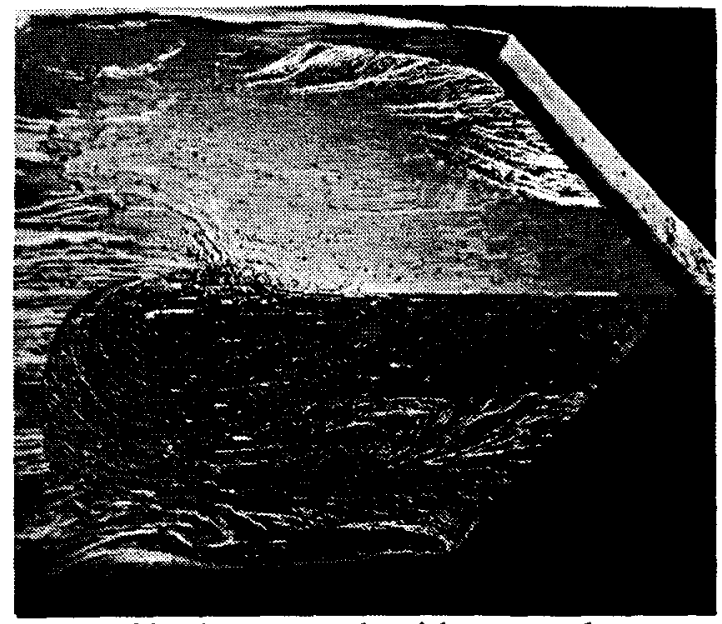

Single sawtooth with external contouring, top view.

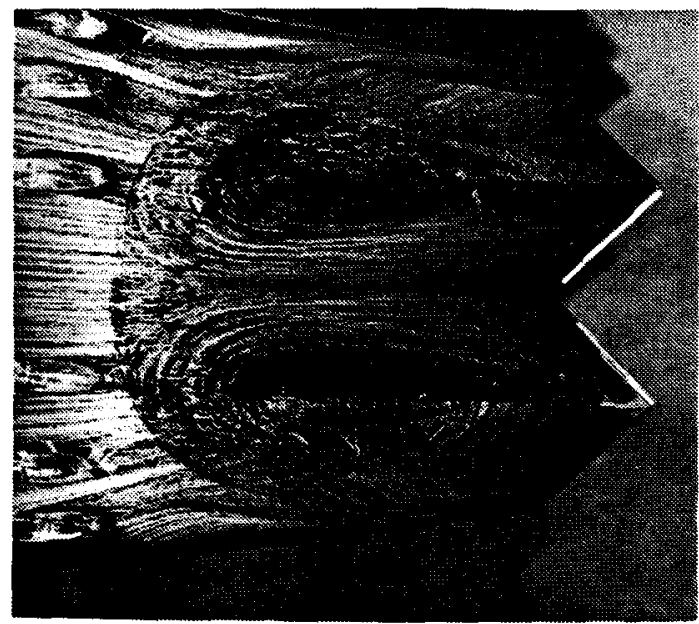

Double sawtooth with external contouring, top view.

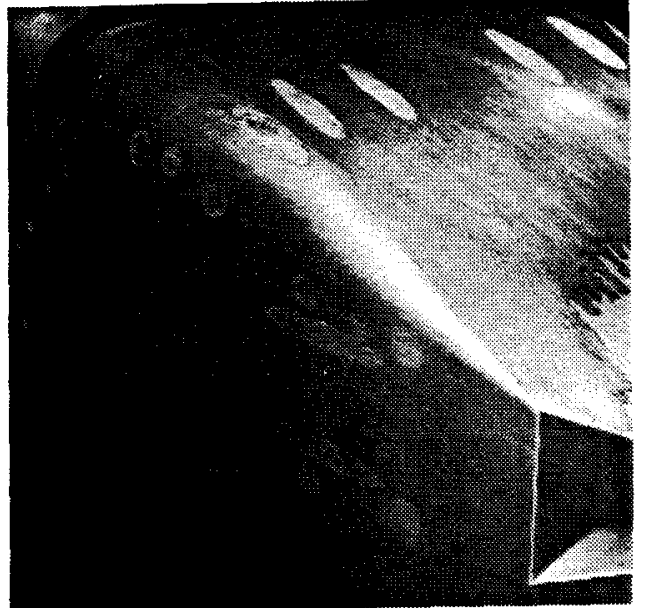

Single sawtooth with internal contouring, three-quater view.

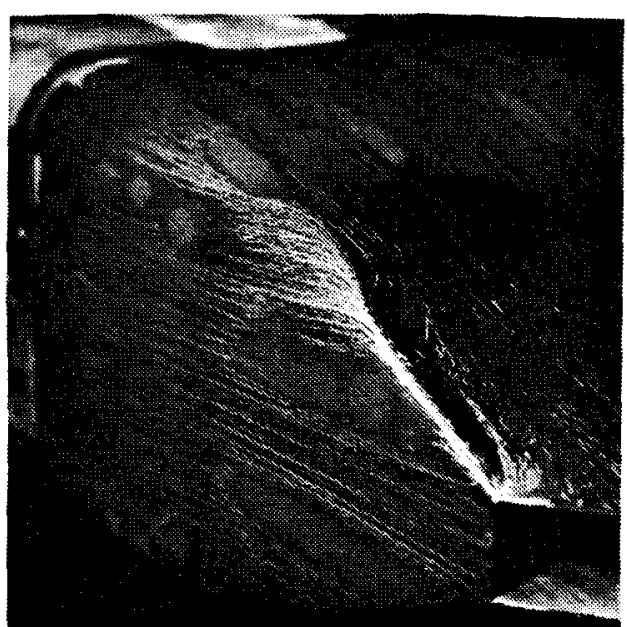

Single sawtooth with external contouring, three-quater view.

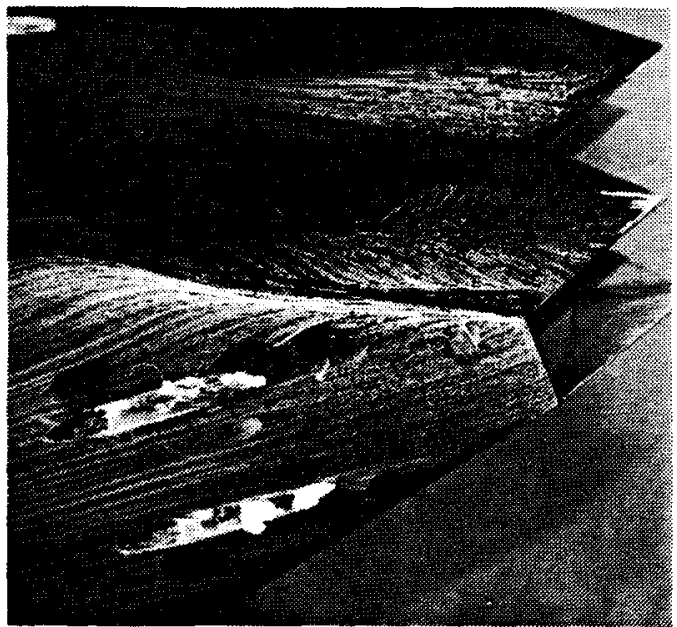

Double sawtooth with external contouring, three-quater view.

Figure 25. Oil, kerosene and dry powder paint mixture flow visualization pattern for $\mathrm{Mach}=0.8$, $\mathrm{NPR}=3.9$ and $\alpha=0.0^{\circ}$ with $\mathrm{A}_{\mathrm{e}} / \mathrm{A}_{\mathrm{t}}=1.2$ for three different configurations. 